\title{
High ferritin levels have major effects on the morphology of erythrocytes in Alzheimer's disease
}

\author{
Janette Bester ${ }^{1}$, Antoinette V. Buys ${ }^{2}$, Boguslaw Lipinski ${ }^{3}$, Douglas B. Kell ${ }^{4}$ and Etheresia Pretorius ${ }^{1 *}$ \\ ${ }^{1}$ Department of Physiology, Faculty of Health Sciences, University of Pretoria, Arcadia, South Africa \\ ${ }^{2}$ Microscopy and Microanalysis Unit, University of Pretoria, Arcadia, South Africa \\ ${ }^{3}$ Joslin Diabetes Center, Harvard Medical School, Boston, MA, USA \\ ${ }^{4}$ School of Chemistry and The Manchester Institute of Biotechnology, The University of Manchester, Lancs, UK
}

\section{Edited by:}

Hari S. Sharma, Uppsala University,

Sweden

\section{Reviewed by:}

Vance G. Nielsen, University of Arizona, USA

Eugene D. Weinberg, Indiana

University, USA

*Correspondence:

Douglas B. Kell, School of Chemistry and The Manchester Institute of

Biotechnology, The University of

Manchester, 131 Princess St.,

Manchester M1 7DN, Lancs, UK

e-mail:dbk@manchester.ac.uk;

Etheresia Pretorius, Department of

Physiology, Faculty of Health

Sciences, University of Pretoria,

Private Bag x323, Arcadia 0007,

South Africa

e-mail: resia.pretorius@up.ac.za
Introduction: Unliganded iron both contributes to the pathology of Alzheimer's disease (AD) and also changes the morphology of erythrocytes (RBCs). We tested the hypothesis that these two facts might be linked, i.e., that the RBCs of $A D$ individuals have a variant morphology, that might have diagnostic or prognostic value.

Methods: We included a literature survey of $A D$ and its relationships to the vascular system, followed by a laboratory study. Four different microscopy techniques were used and results statistically compared to analyze trends between high and normal serum ferritin (SF) AD individuals.

Results: Light and scanning electron microscopies showed little difference between the morphologies of RBCs taken from healthy individuals and from normal SF AD individuals. By contrast, there were substantial changes in the morphology of RBCs taken from high SF AD individuals. These differences were also observed using confocal microscopy and as a significantly greater membrane stiffness (measured using force-distance curves).

Conclusion: We argue that high ferritin levels may contribute to an accelerated pathology in $A D$. Our findings reinforce the importance of (unliganded) iron in $A D$, and suggest the possibility both of an early diagnosis and some means of treating or slowing down the progress of this disease.

Keywords: Alzheimer's disease, erythrocytes, iron, scanning electron microscopy, atomic force microscopy

\section{INTRODUCTION}

There is increasing evidence that vascular components, including RBCs and fibrinogen, play a fundamental role in neurological diseases, including Alzheimer's disease (AD) (Kovacic and Fuster, 2012; Diomedi and Misaggi, 2013; Kling et al., 2013). Erythrocytes (RBCs) are highly deformable, and this physical property contributes significantly to assisting blood flow in the microcirculation, where capillaries may be barely larger than the nominal RBC diameter (Mohandas and Gallagher, 2008). According to one view, the abnormalities in RBCs and their flow contribute to $\mathrm{AD}$ by obstructing oxygen delivery to brain (Tateishi et al., 2001; Mohanty et al., 2008; Tripathy et al., 2013) that, in turn, causes hypoxia leading to a chronic inflammation (Eltzschig and Carmeliet, 2011; Wyss-Coray and Rogers, 2012). Mohanty and co-workers in 2010 noted that there is a potential link between alterations in the RBC membrane proteome in AD subjects and AD pathology (Mohanty et al., 2010). These authors showed that $15 \%$ of RBCs in $\mathrm{AD}$ patients were elongated, and that there were alterations in the RBC membrane architecture. They suggested that this might be due to RBC-beta-amyloid interactions and/or changes in the expression of membrane proteins. Fibrinogen, a plasma precursor of fibrin has been found in the brains of AD patients (Choi et al., 2002) and it was shown that fibrin also interacted with beta-amyloid protein (Merkle et al., 1996) in such patients. There is also evidence in $\mathrm{AD}$ that perivascular leakage of fibrinogen happens in $\mathrm{AD}$ and more importantly that fibrin accelerates neurovascular damage (Paul et al., 2007).

Closely linked to hematological pathology in $\mathrm{AD}$ are increased iron levels, that also play an important role in the pathogenesis of the condition (Barnham and Bush, 2008; Smith et al., 2010; Weinberg, 2010). Increased iron levels cause oxidative stress, as they participate in oxygen-dependent free radical formation (Kell, 2009). Free radical stresses, and specifically those from hydroxyl radicals, are important factors in the pathogenesis of $\mathrm{AD}$, as they lead to protein modification and consequently to neuronal damage (Casadesus et al., 2004; Castellani et al., 2012). This free radical stress may also impact on RBCs, and this may cause extensive and accumulative damage to these cells, ultimately compromising their functioning. Optimal oxygen delivery to the brain clearly depends on optimal RBC physiology (Tateishi et al., 2001). Finally, here, increased RBC aggregation and sedimentation, as well as flow abnormalities, have been observed in the blood of patients with degenerative diseases such as atherosclerosis and inflammation, that are also known to be associated with $\mathrm{AD}$ (Robinson et al., 1995; Andresdottir et al., 2003; McMahon et al., 2013).

We have shown previously that when iron overload is present in conditions such as diabetes and hereditary hemochromatosis, 
RBCs are distorted, and form pointed extensions (Lipinski et al., 2012a; Pretorius, 2013; Pretorius and Lipinski, 2013). This change in morphology (and perhaps deformability-see below) may play a fundamental role in the thrombotic and cardiovascular risk typically seen in these and other conditions. In diseases such as thalassemia and hereditary hemochromatosis (Carpenter et al., 2013), literature also suggests the prevalence of cardiac complications (Noori et al., 2012; Maggio et al., 2013) and thrombocytosis with increased risk of stroke (Shariat et al., 2013). Also, we have previously shown that a changed RBC, platelet and fibrin network ultrastructure is present in stroke (Lipinski et al., 2012b; Swanepoel and Pretorius, 2012).

During wound healing and the consequent activation of the coagulation pathway, a fibrin net is created (Weisel, 2005). Thrombin is part of the relevant cascade that facilitates the conversion (Undas and Ariëns, 2011), and is involved in the normal final step that converts soluble fibrinogen to the resulting fibrin net (Davalos and Akassoglou, 2012). Under laboratory conditions, this fibrin fiber net can be simulated by adding thrombin to either whole blood or plasma (Pretorius et al., 2013c). In healthy individuals, these fibers form a net that lies on top of and around the discoid RBCs. However, in the presence of iron overload, the RBCs are folded and twisted around the fibers, suggesting structural changes to these fibers and/or cells. The fibers are also more compact, and rather than a net, form dense matted deposits known as "atypical parafibrin" (Lipinski and Pretorius, 2013; Pretorius et al., 2013a). When physiological levels of unliganded ferric iron are added to healthy whole blood, the resulting parafibrin becomes resistant to the normal pathways of fibrin degradation (Pretorius and Lipinski, 2013). Also, the RBCs show the same ultrastructure as in iron overload, where they twist around fibers. The structural changes in RBCs in the presence of iron overload, may impact on the rheological properties of the cells. Previously, it was noted in hereditary hemochromatosis, that there is a higher plasma viscosity, resulting in damage to red cells at the level of microcirculation (Ershova et al., 1998). In the light of the compelling evidence that (i) RBCs and fibrin are changed in iron overload, and (ii) that iron is involved in the pathogenesis of $\mathrm{AD}$, we here investigate the hypothesis that in $\mathrm{AD}$, especially in the presence of iron overload, the morphology of RBCs is also altered significantly, and that one may contribute to the other.

Because iron is implicated in $\mathrm{AD}$, serum ferritin (SF) levels of each patient were also measured. Iron deposition in various organs, ultimately resulting in end-organ damage, including arthralgias, osteoporosis, cirrhosis, hepatocellular cancer, cardiomyopathy, dysrhythmia, diabetes mellitus, and hypogonadism (Crownover and Covey, 2013; Kanwar and Kowdley, 2013) has been linked directly to elevated SF levels (Kanwar and Kowdley, 2013). Also, SF above $150 \mathrm{ng} / \mathrm{mL}^{-1}$ (females) or $300 \mathrm{ng} / \mathrm{mL}^{-1}$ (males) is taken as iron overload (Kellner and Zoller, 1992; Koziol et al., 2001; Adams et al., 2005, 2006; Adams, 2008; Jacobs et al., 2009; Gordeuk et al., 2012; Crownover and Covey, 2013). Light microscopy was used to study the general morphology of the erythrocytes, and their axial ratios were measured to determine variation in shape. Also, scanning electron microscopy (SEM) analysis of RBCs was performed to determine interactions between erythrocytes and fibrin. Furthermore, the presence of spontaneous hypercoagulability, visible as dense matted fibrin deposits (DMDs), and ultrastructural erythrocyte membrane changes were also studied. The deformability of the cell membranes was determined using atomic force microscopy (AFM). Finally, confocal microscopy was used to study the permeability of erythrocyte membranes to a particular dye, to assess the presence of membrane damage. Overall, we found that many AD patients have an increased SF level, and that the RBCs of these individuals differed significantly in both ultrastructural properties and membrane elasticity, as well as in terms of membrane permeability, from those taken from healthy as well as those from $\mathrm{AD}$ individuals with normal SF levels.

Thus, in the current work we studied the blood of $25 \mathrm{AD}$ patients and of 40 healthy individuals. This manuscript is structured as follows (see Figure 1, based on the desirability of an overview figure (Wong, 2011): we start with a literature survey of $\mathrm{AD}$ and its relationships to the vascular system, particularly the role of RBCs. Then we assessed the SF levels in $\mathrm{AD}$ patients. We used four different microscopy techniques to study whole blood from $\mathrm{AD}$ patients and compared these to samples taken from healthy individuals. Finally we correlated the microscopy results with SF levels in our AD individuals.

\section{MATERIALS AND METHODS VOLUNTEER DETAILS}

Bloods were obtained from fully diagnosed Alzheimer's patients. All donors so designated had been diagnosed with AD by qualified medical practitioners and did not smoke. Specifically, a neurologist diagnosed all $\mathrm{AD}$ individuals that included the patient history, as well as the Mini Mental State Examination (MMSE) (Table 1 shows their history and SF levels, while Table 2 shows the summary characteristics of the sample. While the average age and gender balance differed between controls and $\mathrm{AD}$ patients, they were well matched between low-SF and high-SF AD patients, which is what is of interest here). A recent study suggested that there are increased markers of iron deposition (including SF levels) and oxidative stress in patients with cognitive dysfunction (Umur et al., 2011). Furthermore, the authors suggested that it seems likely that these markers had a negative effect on the MMSE score (Smith et al., 2010; Bartzokis et al., 2011; Umur et al., 2011; Penke et al., 2012). Ethical clearance was obtained from the Health Sciences Ethical committee from the University of Pretoria and informed consent was obtained from family members who act as guardians of the patients. Healthy individuals also filled in consent forms.

Blood $(6 \mathrm{~mL})$ was collected in a citrate tube and also $6 \mathrm{~mL}$ were collected in a tube for serum iron level determination. The $\mathrm{AD}$ patients were divided into two groups (normal and high SF levels, high "high SF" being defined as a level of $>150 \mathrm{ng} \cdot \mathrm{mL}^{-1}$ for females and $300 \mathrm{ng} \cdot \mathrm{mL}^{-1}$ for males). Healthy individuals were identified and they also did not smoke or have any chronic conditions, their ages varied from 19 to 79. Ethical approval was granted at the University of Pretoria (HUMAN ETHICS COMMITTEE: FACULTY OF HEALTH SCIENCES) under the name J. Bester. Written informed consent was obtained from all healthy individuals used as controls. Written consent was 


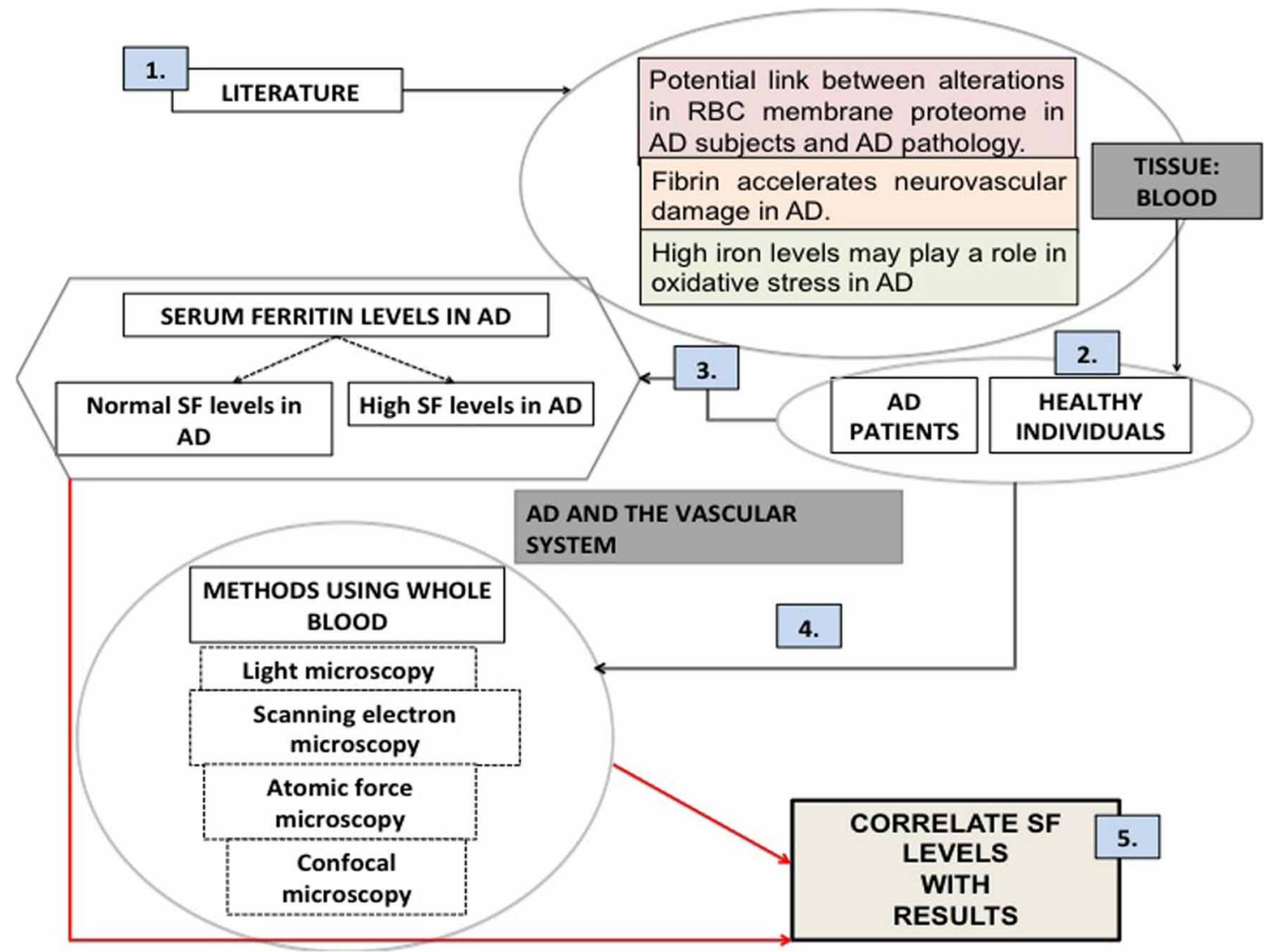

FIGURE 1 | An overview figure summarizing the contents of this manuscript. (1) Literature suggests that there is a rationale for looking at the vascular system and particularly blood; (2) our sample was chosen to be a random group of Alzheimer's individuals (AD), as well as healthy individuals;
(3) (unliganded) iron has been implicated in the literature as a role player in $A D$; serum ferritin levels were measured; (4) our methodologies included various microscopy techniques; (5) finally we correlated our microscopy results to the presence of high serum ferritin levels. obtained from a family member who is responsible for the care of each $\mathrm{AD}$ individual.

\section{LIGHT MICROSCOPY AND AXIAL RATIOS}

Thin LM smears were made followed by air-drying, fixing in methanol, and staining with Methylene blue and Eosin (Copenhaver et al., 1971). Slides were mounted with Entellan and viewed with a Nikon Optiphod transmitted light microscope (Nikon Instech Co., Kanagawa, Japan). Axial ratios of RBCs from 40 healthy individuals, as well as the two $\mathrm{AD}$ groups were captured using Image J (ImageJ is a public domain, Java-based image processing program developed at the National Institutes of Health: http://rsbweb.nih.gov/ij/). Axial ratios were always greater than (or equal to) 1 by using the largest diameter overall as the numerator, and as the denominator the length at $90^{\circ}$ to the line used to provide the numerator. On average, $20 \mathrm{RBCs}$ were assessed for each individual. A box plot, which is a descriptive statistical method (and other statistics) were calculated using MS-Excel, together with the add-in template downloadable from http://www.vertex42.com/. P-values were calculated from the means, the numbers of objects measured in each class and the standard deviations using the Excel add-in available via http://www.talkstats.com/attachment.php? attachmentid $=261 \& \mathrm{~d}=1213281245$ and the facility at http:// www.graphpad.com/quickcalcs/ttest $1 . c f m$ ?Format=SD.

\section{SCANNING ELECTRON MICROSCOPY (SEM)}

After the blood was collected, $10 \mu \mathrm{l}$ of whole blood were placed directly on a glass cover slip, fixed, dehydrated, dried, mounted and coated with carbon according to previously described methods (Buys et al., 2013). Additionally, $10 \mu$ l of whole blood (WB) was mixed with $5 \mu$ l of thrombin, to create an extensive fibrin network in between the RBCs. A Zeiss ULTRA Plus FEG-SEM with InLens capabilities was used to study the surface morphology of erythrocytes, and micrographs were taken at $1 \mathrm{kV}$.

\section{ATOMIC FORCE MICROSCOPY (AFM)}

WB in a citrate tube was centrifuged at $145 \times \mathrm{g}$ for $30 \mathrm{~s}$. The supernatant (plasma, platelets, and white blood cells) were discarded and the remaining RBC's were prepared for AFM by fixing in $4 \%$ formaldehyde (made up in PBS) for $30 \mathrm{~min}$, at room temperature $\left(22^{\circ} \mathrm{C}\right)$ followed by dehydration and placing a drop of the RBC's suspended in undiluted $(161.39 \mathrm{~g} / \mathrm{mol})$ hexamethyldisilazane (HMDS) onto a glass cover-slip and spreading the fluid 
Table 1 | Serum ferritin levels (SF) of Alzheimer's (AD) patients, history and corresponding figure numbers.

\begin{tabular}{llll}
\hline AD individual & $\begin{array}{l}\text { AD diagnosed in years } \\
\text { gender and age }\end{array}$ & $\begin{array}{l}\text { SF } \\
\text { and previous medical } \\
\text { conditions }\end{array}$ & $\begin{array}{l}\text { Corresponding } \\
\text { figure }\end{array}$ \\
\hline
\end{tabular}

\begin{tabular}{|c|c|c|c|}
\hline \multicolumn{4}{|c|}{ AD WITH NORMAL SF } \\
\hline $\mathrm{F} ; 74$ & $\begin{array}{l}\text { 4; previous thrombotic } \\
\text { stroke }\end{array}$ & 49 & Figure 3 \\
\hline$F ; 59$ & 6; epilepsy & 58 & \\
\hline$F ; 91$ & 10; Osteoporosis & 32 & \\
\hline$F ; 85$ & 3; none & 17 & \\
\hline$F ; 67$ & 1.5; high blood pressure & 130 & $\begin{array}{l}\text { Figure } 2(4) ; \\
\text { Figure } \mathbf{6 C}(4)\end{array}$ \\
\hline$F ; 76$ & 13; hypothyroidism & 94 & Figure $6 \mathrm{~B}(3)$ \\
\hline$F ; 83$ & 3; hypothyroidism & 57 & Figure $2(3)$ \\
\hline$F ; 93$ & $\begin{array}{l}\text { 13; hypothyroidism; } 3 \\
\text { heart attacks }\end{array}$ & 128 & Figure $6 \mathrm{~B}(2)$ \\
\hline$F ; 80$ & $\begin{array}{l}\text { 12; hypothyroidism; high } \\
\text { blood pressure }\end{array}$ & 29 & Figure 2 (1) \\
\hline$F ; 67$ & $\begin{array}{l}\text { 8; high blood pressure; } \\
\text { high cholesterol }\end{array}$ & 101 & $\begin{array}{l}\text { Figure } 2(2) ; \\
\text { Figure 6B (1) }\end{array}$ \\
\hline \multicolumn{4}{|c|}{ AD WITH HIGH SF } \\
\hline$M ; 60$ & 1 ; high cholesterol & 359 & \\
\hline$F ; 84$ & 10; kidney atrophy & 302 & Figures 4B,C \\
\hline$F ; 96$ & $2 ;$ none & 256 & Figure 2 (3) \\
\hline $\mathrm{F} ; 77$ & $\begin{array}{l}\text { 2; asthma; high blood } \\
\text { pressure; osteoporosis }\end{array}$ & 173 & Figure 2 (2) \\
\hline $\mathrm{F} ; 76$ & 7; high cholesterol & 194 & Figure $6 \mathrm{C}(2)$ \\
\hline$M ; 74$ & 4; depression & 311 & Figure $6 \mathrm{C}(4)$ \\
\hline M; 80 & $\begin{array}{l}\text { 15; thrombotic stroke; } \\
\text { high blood pressure }\end{array}$ & 187 & \\
\hline$F ; 85$ & $3 ;$ none & 189 & \\
\hline$F ; 93$ & $\begin{array}{l}3 \text {; hypothyroidism; heart } \\
\text { bypass }\end{array}$ & 240 & Figure 2 (4) \\
\hline F; 88 & $\begin{array}{l}\text { 4; hypothyroidism, high } \\
\text { blood pressure; } \\
\text { osteoporosis }\end{array}$ & 153 & \\
\hline$F ; 89$ & 10; high blood pressure & 300 & Figure 4A \\
\hline$F ; 86$ & 9; high blood pressure & 244 & Figure $6 \mathrm{C}(3)$ \\
\hline$F ; 78$ & 10; none & 423 & \\
\hline$F ; 75$ & 8; high blood pressure & 371 & $\begin{array}{l}\text { Figure } 2(1) ; \\
\text { Figure } 6 \mathrm{C}(1)\end{array}$ \\
\hline$F ; 80$ & 7; back problems & 196 & \\
\hline
\end{tabular}

by tilting the coverslip sideways, ensuring an even distribution of cells. Cover slips were dried and stored until AFM analysis.

Characterization of the cells was performed with a commercial AFM system (Dimension Icon with ScanAsyst, Bruker, USA) using the PeakForce QNM (Quantitative Nanomechanical Property Mapping) imaging mode. This method is similar to the standard tapping mode of scanning probe microscopy, where the probe and the sample are brought together intermittently, but in contrast to the more classical tapping mode (where the oscillation amplitude is kept constant), this mode operates by controlling the maximum force applied by the probe to the sample (Dufrêne et al., 2013). At every pixel a rapid force-distance curve is performed and as the cantilever's deflection sensitivity and spring constant is calibrated before measurements, the curve can be analyzed quantitatively to obtain a series of specific property maps of the sample (Figure 2). Thus, the retract curve is used to calculate modulus and adhesion images (slope of the curve and the minimum of the curve, respectively), the variation between the zero and maximum force is used to calculate deformation and the area between the approach and retract curve can be used to calculate energy dissipation (Berquand, 2011; Kolar et al., 2013). Thus, the retract curve is used to calculate modulus and adhesion images (slope of the curve and the minimum of the curve, respectively), the variation between the zero and maximum force is used to calculate deformation, also energy dissipation can be measured as tip-sample interactions cause hysteresis between the approach and retract curves and by measuring the area between these curves the loss of mechanical energy can be determined.

The Young's modulus is a measure of the stiffness of an elastic material and can generally be defined as stress divided by the corresponding strain, with greater values indicating increased stiffness or decreased deformability. As each force curve's data can also be stored individually, it is possible to obtain quantitative measurements of the Young's modulus by fitting the slope of any force distance curve of the image to an appropriate model (in this instance; the Derjaguin-Muller-Toporov (DMT) Model (Derjaguin et al., 1975). Silicon Nitride probes (TAP525MPP 13120-10, Bruker, USA) with a nominal force constant of $200 \mathrm{~N} \cdot \mathrm{m}^{-1}$, a resonant frequency between 430 and $516 \mathrm{kHz}$ (measured by the manufacturer), and a nominal tip radius of $15 \mathrm{~nm}$ were employed in all AFM measurements. Ten cells from a minimum of 7 individuals out of each group (see Table 3 ) were analyzed by selecting a $1 \mu \mathrm{m}$ by $1 \mu \mathrm{m}$ scan area on the periphery of the RBC and performing 128 by 128 data points of individual force curve measurements with a peak force of $6 \mu \mathrm{N}$. The periphery of the cells was chosen as there might be differences in concavity of RBCs, and we therefore chose an area that is not affected by the concavity of the specific RBC. The scans were performed at $0.6 \mathrm{~Hz}$, which translates to a tip velocity of $1.2 \mu \mathrm{m} \cdot \mathrm{s}^{-1}$ and 25-35 force curves were chosen randomly within the stated area. Offline software (NanoScope Analysis version R3, Bruker, USA) was used to process the force curves and fit the modulus model to the unloading portion (red curve, using the green section marked in Figure 2 of the "retraction" curve). The goodness of fit $\left(R^{2}\right)$ between the modulus model and the data given by the acquired curve is determined by calculating the ratio of explained variation to total variation in the dataset; only force curves with a goodness of fit so defined of 0.85 and above were used for modulus measurements. The statistical significance of the difference between calculations was determined using one-way analysis of variance. A $P$-value of less than 0.05 relative to the null hypothesis was considered to be "significant" [cf. (Broadhurst and Kell, 2006)], and $P$-values are noted.

\section{CONFOCAL MICROSCOPY}

Confocal microscopy was used to determine if membrane damage could be detected using a specific membrane marker. Unfortunately, there is a limited availablilty of specific markers for RBCs and their membranes. We identified the use of LIVE/DEAD Fixable Dead Cell Stain from Life Technologies ${ }^{\mathrm{TM}}$ as 
Table 2 | Summary characteristics of healthy individuals and Alzheimer's disease individuals.

\begin{tabular}{|c|c|c|c|}
\hline & Healthy individuals $(n=40)$ & $\begin{array}{l}\text { Normal serum ferritin } \\
\text { AD individuals }(n=11)\end{array}$ & $\begin{array}{l}\text { High serum ferritin AD } \\
\text { individuals }(n=14)\end{array}$ \\
\hline Average age and range & $26,19-79$ & $78,59-91$ & $81,60-96$ \\
\hline Male: female & $22: 18$ & $1: 10$ & $2: 12$ \\
\hline Serum ferritin levels and range & $\begin{array}{l}<150 \mathrm{ng} \cdot \mathrm{mL}^{-1} \text { for females and } \\
300 \mathrm{ng} \cdot \mathrm{mL}^{-1} \text { for males }\end{array}$ & $80,17-187$ & $265,154-423$ \\
\hline Smoker: non-smoker & $0: 40$ & $0: 11$ & $1: 13$ \\
\hline Etiology ischemic/non-ischemic & $0: 40$ & $2: 9$ & $0: 14$ \\
\hline Hypertensive: Normotensive & $0: 40$ & $4: 7$ & $5: 9$ \\
\hline ACE-inhibitors: yes/no & $0: 40$ & $4: 7$ & $3: 11$ \\
\hline Beta-blockers: yes/no & $0: 40$ & $1: 10$ & $1: 13$ \\
\hline Hypothyroid: yes/no & $0: 40$ & $4: 7$ & $2: 12$ \\
\hline Epilepsy: yes/no & $0: 40$ & $1: 10$ & $0: 14$ \\
\hline Osteoporosis: yes/no & $0: 40$ & $1: 10$ & $1: 13$ \\
\hline
\end{tabular}

Normal SF females: $10-150 \mathrm{ng} \cdot \mathrm{mL}^{-1}$; males: $12-300 \mathrm{ng} \cdot \mathrm{mL}^{-1}$; Normal ranges for low density lipoprotein (LDL) < $1.8 \mathrm{mmol} \cdot \mathrm{L}^{-1}$; high density lipoprotein: > $1.6 \mathrm{mmol} / \mathrm{L}$; total cholesterol $<5.2 \mathrm{mmol} \cdot \mathrm{L}^{-1}$; ischemic vs. non-ischemic: individual had at least 1 thrombotic event in his/her lifetime; non-ischemic: no thrombotic event; normal blood pressure: $80 / 120 \mathrm{mmHg}$. Hypothyroidism: thyroid stimulating hormone $(\mathrm{TSH})>5.5 \mu \mathrm{lU} / \mathrm{mL}$.

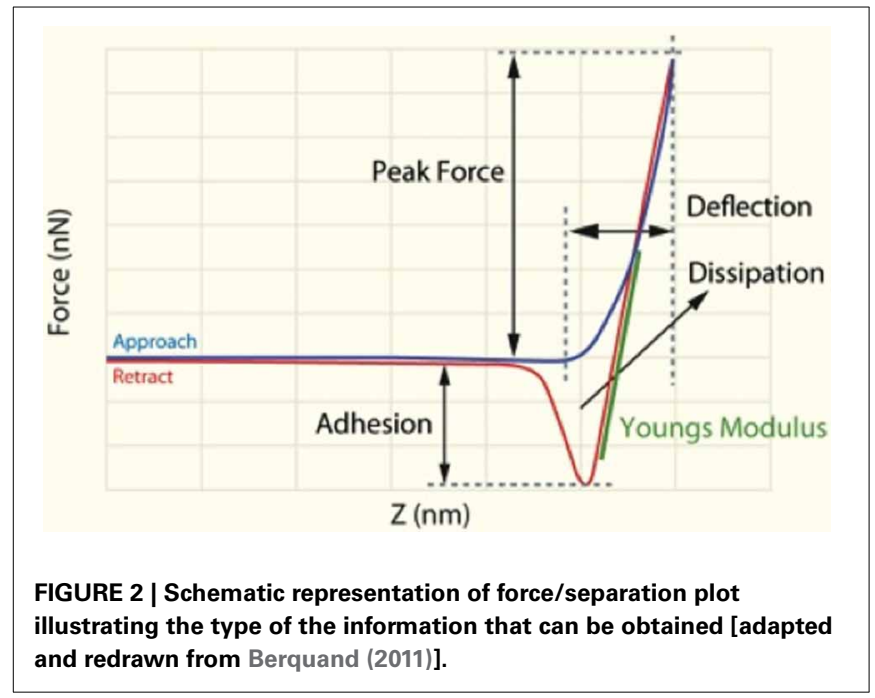

a possible marker for membrane damage. This stain kit is based on the reaction of a fluorescent reactive dye with intracellular and extracellular amines. The reactive dye can permeate membranes compromised before fixation and react with free amines both in the interior and on the cell surface, resulting in intense fluorescent staining (Perfetto et al., 2010). In viable cells, only the exterior cell-surface amines are available to react with the dye, resulting in relatively dim staining. The influence of cell type and marker specificity on the stability of fluorescence intensity after fixation has not been well studied and fluorescence stability should be determined for each cell type and marker used (Stewart et al., 2007). Therefore, we optimized the method specifically to use
Table 3 | Descriptive statistics for elasticity (MPa) of red blood cell (RBC) membranes as obtained from the atomic force microscopy (AFM).

\begin{tabular}{llll}
\hline Analysis & Control & High SF AD & Normal SF AD \\
\hline Mean & 46,711 & 53,465 & 45,706 \\
Standard deviation & 39,211 & 49,711 & 45,473 \\
Standard error & 750 & 1228 & 788 \\
$P$-value (vs. control) & - & $6.6 \cdot 10^{-7 *}$ & 0.3 \\
$N$ (individuals) & 11 & 7 & 10 \\
$P$-value (high SF AD vs. & & $4.4 \cdot 10^{-8 *}$ & \\
normal SF AD) & & & \\
$N$ (cells) & 110 & 72 & 100 \\
$N$ (curves) & 2737 & 1639 & 3331 \\
\hline
\end{tabular}

${ }^{*}$ Significant p-value.

blood fixed and stored in $4 \%$ formaldehyde. For this, we used fresh and fixed blood ( $4 \%$ formaldehyde) of three healthy individuals, as well as of an individual with high SF levels diagnosed with hemochromatosis $\left(S F=33000 \mathrm{ng} \cdot \mathrm{mL}^{-1}\right)$. Before we added the dye, we washed the fixed samples, $3 \times$ with PBS to eliminate formaldehyde residues. No difference in fluorescence intensity was noted between the fixed and fresh samples, except that the fluorescence faded within a minute in the fresh samples.

In the current study, the RBCs were fixed and stored in $4 \%$ formaldehyde. When confocal microscopy was done, the cells were washed $3 \times$ in PBS and vortexed to form a pellet. $100 \mu l$ of RBCs was then re-suspended in $100 \mu \mathrm{l}$ PBS. $0.2 \mu \mathrm{l}$ of LIVE/DEAD Fixable Dead Cell Stain (from Life Technologies) was added to $20 \mu \mathrm{l}$ RBCs in PBS and incubated at room temperature, in the 
dark for $20 \mathrm{~min} .5 \mu \mathrm{l}$ of the sample were mounted and viewed using a Zeiss LSM 510 META confocal microscope with a PlanApochromat $63 \times / 1.4$ Oil DIC objective with wavelengths of $488 \mathrm{~nm}$ and $514 \mathrm{~nm}$. Confocal micrographs were analyzed using the Image fluorescence measuring function, where we determined the level of fluorescence. We calculated the corrected total cell fluorescence (CTCF) for each patient and then the mean for each of the 3 groups. This is done with the following formula: $\mathrm{CTCF}=$ mean integrated density $-($ mean area of selected cells $\mathrm{X}$ mean fluorescence of background readings).

\section{RESULTS}

Table 1 shows the outline medical history of the AD individuals, as well as their SF levels, while Table 2 shows statistical summary characteristics. None of the individuals was considered (as discussed with their neurologist) to have major health complications that might bias the analysis. Figure 3 shows the axial ratios of the erythrocytes, depicted as box plots, together with descriptive statistics. There are no significant shape difference between the erythrocytes of controls and of those taken from $\mathrm{AD}$ individuals with normal levels of SF, however, there are highly significant differences between the axial ratios of both control vs. high SF $\mathrm{AD}$ individuals and between the axial ratios of the erythrocytes of normal SF and of high SF AD individuals. Figure 4 shows light microscopy smears of four healthy individuals and also four normal and four high SF AD individuals. In these micrographs, healthy individuals show the typical discoid RBC shape. This is also seen in the normal SF AD individuals. However, a large fraction of the RBCs of the high SF AD individuals have an elongated, non-discoid RBC shape, as previously seen for erythrocytes taken from individuals with iron overload (Pretorius and Lipinski, 2013).

Analysis of RBCs using SEM (Figures 5-7) confirmed the LM results, and showed that the RBCs of normal SF AD individuals

CONTROLS
Normal SF AD

typically have a discoid shape, and appear no different from the RBCs of healthy individuals. When thrombin is added to whole blood of healthy individuals, the RBCs retain their discoid shape (Figure 5B) (Pretorius, 2013); the same was found for whole blood from the normal SF AD patients (Figure 6B). However, when looking at the RBCs of high SF AD individuals, these were seen to form pointed extensions and to have a slight elongation (in WB smears); this was also noted in LM smears (Figures 4, 6A,B). Also, in the presence of fibrin fibers, generated after addition of thrombin, the RBCs fold around the fibers (Figure 7D), and areas of thickened and matted fibrin or DMDs are also noted (Figure 7D). This changed fibrin ultrastructure, where fibrinogen coagulates to form matted plates rather than individual fibrin fibers (that were also thinner), has previously been noted in both thrombo-embolic ischemic stroke and diabetes (Lipinski et al., 2012b; Buys et al., 2013), as well as in the presence of exogenously added unliganded Fe(III) (Pretorius et al., 2013c).

High $(150,000 \times)$ SEM magnifications of RBC membranes show that the membrane surface of healthy cells has a typical globular structure (Pretorius, 2013; Pretorius et al., 2013b) (Figure 5C); this was also found for normal SF AD individuals (Figure 6C). The membranes of RBC from high SF AD individuals were more granular, when studied at 150,000× magnification (compare Figures 6C, 7C). This implies that the membrane architecture is changed and that possibly the elasticity and membrane integrity might be compromised. Therefore, because significant changes in membrane ultrastructure were seen when viewed at very high SEM magnification, we were interested to see if these changes were accompanied by any other alterations in the RBC membrane, which may result in changed mechanical properties of the cell.

Force-distance curves [see (Dufrêne et al., 2013) and above], and subsequent modulus value calculations, were used to assess this. Elastic modulus calculations (Table 2) showed that the Young's modulus of RBCs taken from high SF AD individuals $(53,465 \mathrm{MPa})$ is statistically significantly higher than the Young's

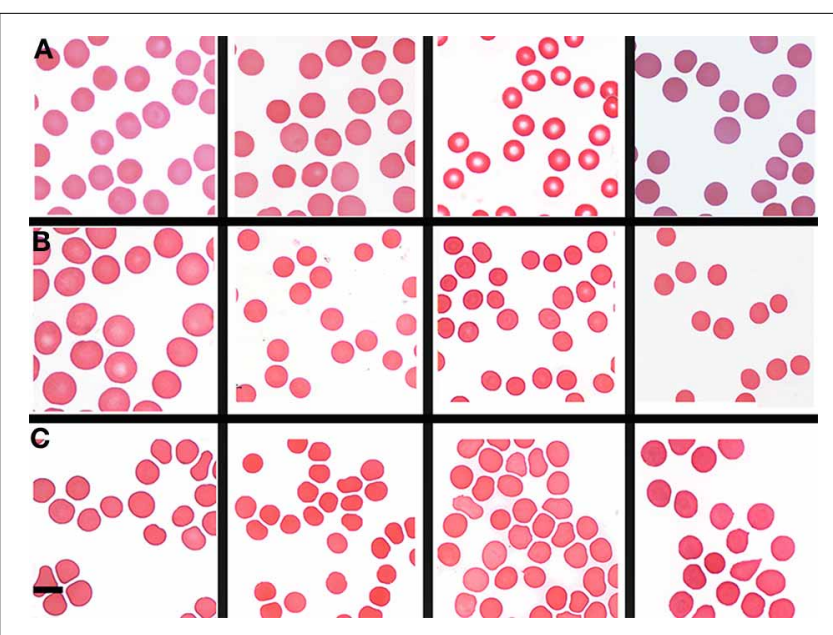

FIGURE 4 | Light microscopy smears of (A) four healthy individuals and (B) four normal and (C) four high normal serum ferritin (SF) Alzheimer's (AD) individuals. Scale $=5 \mu \mathrm{m}$. 

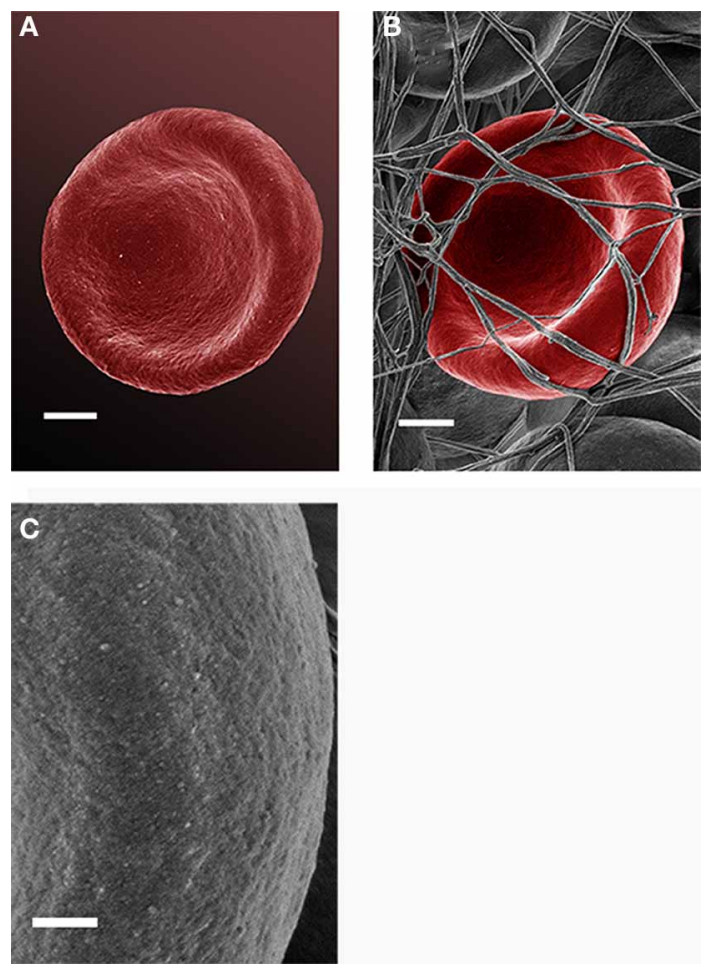

FIGURE 5 | Scanning electron microscopy (SEM) micrographs of a typical healthy red blood cell (scale $=1 \mu \mathrm{m}$ ) (A). RBC that is discoid in shape when thrombin is added to whole blood (scale $=1 \mu \mathrm{m})(\mathbf{B})$; high magnification of RBC membrane, showing globular structure; (C) (Scale $=100 \mathrm{~nm}$ ).
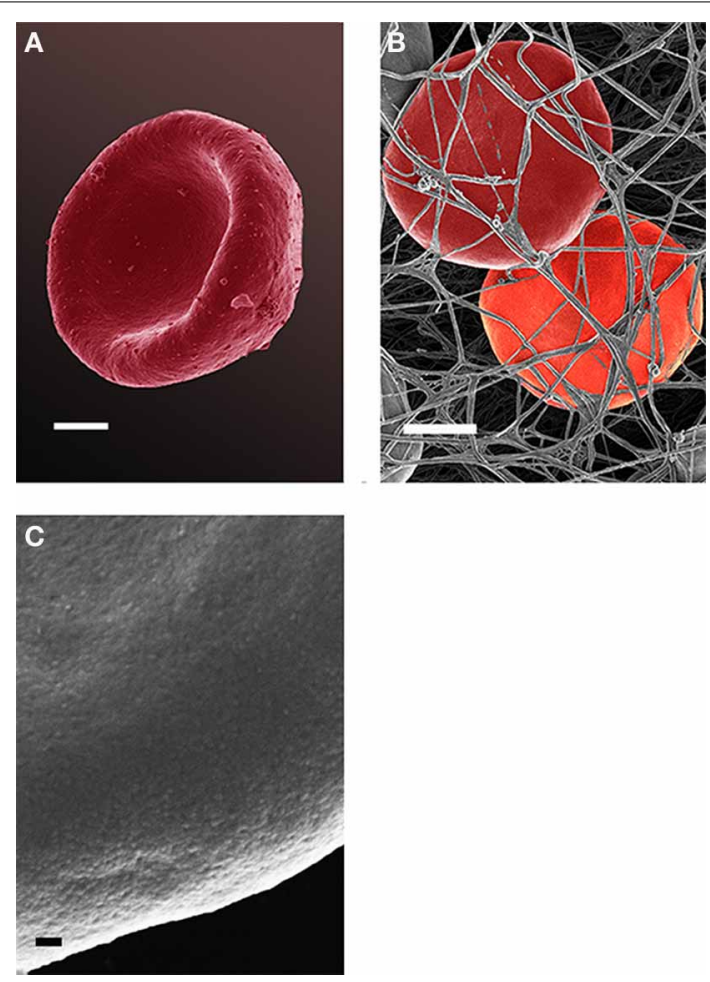

FIGURE 6 | Red blood cell from a normal SF AD individual (scale $=1 \mu \mathrm{m}$ ) (A); where thrombin is added to whole blood; the cells keep their discoid shape (scale $=1 \mu \mathrm{m}$ ) $\mathbf{( B )}$; high magnification of RBC membrane, showing globular structure (Scale $=100 \mathrm{~nm}$ ) (C). modulus values observed in control and normal SF AD RBCs (46,711 and 45,706 MPa, respectively). This ca 15\% increase in the Young's Modulus, meaning there is a decrease in elasticity, can also be seen directly in the typical force-distance curves (Figure 8), where a steeper slope and decreased probe displacement of the high SF RBC curve is evident.

Because the changes in mechanical stiffness of the RBCs of AD patients with high SF might reasonably be expected to be reflected in changes in other membrane properties, we then sought to assess the membrane permeability of the different RBC (before fixation) using a so-called LIVE/DEAD Fixable Dead Cell Stain. The LIVE/DEAD Fixable Dead Cell Stain can bind to amines on the outer membrane of the cell but when membrane integrity is compromised it may enter the cell to bind to amines typically found inside the cell. When this happens, the damaged cells will show a higher green fluorescence. To compare confocal microscopy data of RBCs from healthy individuals with those from individuals with $\mathrm{AD}$ and normal and high SF, we show micrographs from six individuals in each of the three groups (Figure 9). Confocal microscopy showed that there is substantially higher fluorescence intensity in RBCs from the high SF AD individuals relative to that in RBCs taken from the controls or the normal SF AD individuals. Analysis of confocal micrographs with ImageJ showed the CTCF for each of the groups. A $t$-test was performed at 5\% level of significance (i.e., where a $P=0.05$ is considered as significant). On this basis, there is no significant difference between the CTCF of healthy individuals vs. that of normal SF AD individuals ( $p=0.89$ ), however, there is a significant difference between the CTCF of healthy individuals and of high SF AD patients (0.04) as well as between normal SF and high SF AD individuals.

To determine if there is any correlation between the severity of the disease manifestations and other variables, we graded the light microscopy smears independently (Table 4). We used three stages, namely normal discoid shape $(\mathrm{N}$, typically seen in healthy individuals), slightly affected (S), and severely affected (A). There was no especially obvious relationship between the morphological grades and either the age at onset or the duration of the Alzheimer's. However, the SF levels were noticeably greater as the cells moved from grades $\mathbf{N}\left(67 \pm 35 \mathrm{ng} \cdot \mathrm{mL}^{-1}\right.$, mean \pm $S D)$ through $\mathbf{S}\left(202 \pm 91 \mathrm{ng} \cdot \mathrm{mL}^{-1}\right)$ to $\mathbf{A}\left(28083 \pm \mathrm{ng} \cdot \mathrm{mL}^{-1}\right)$. Visualizations were also performed using the Tibco/Perkin Elmer Spotfire software, where the trends once again showed that the severity of the RBC changes are clearly linked to the SF levels (Figure 10).

\section{DISCUSSION}

Iron overload is associated with many pathological conditions, including liver and heart diseases, neurodegenerative disorders, diabetes, hormonal abnormalities immune system abnormalities, heart failure, and in particular in the more classical conditions recognized as "iron overload" diseases such as hereditary 

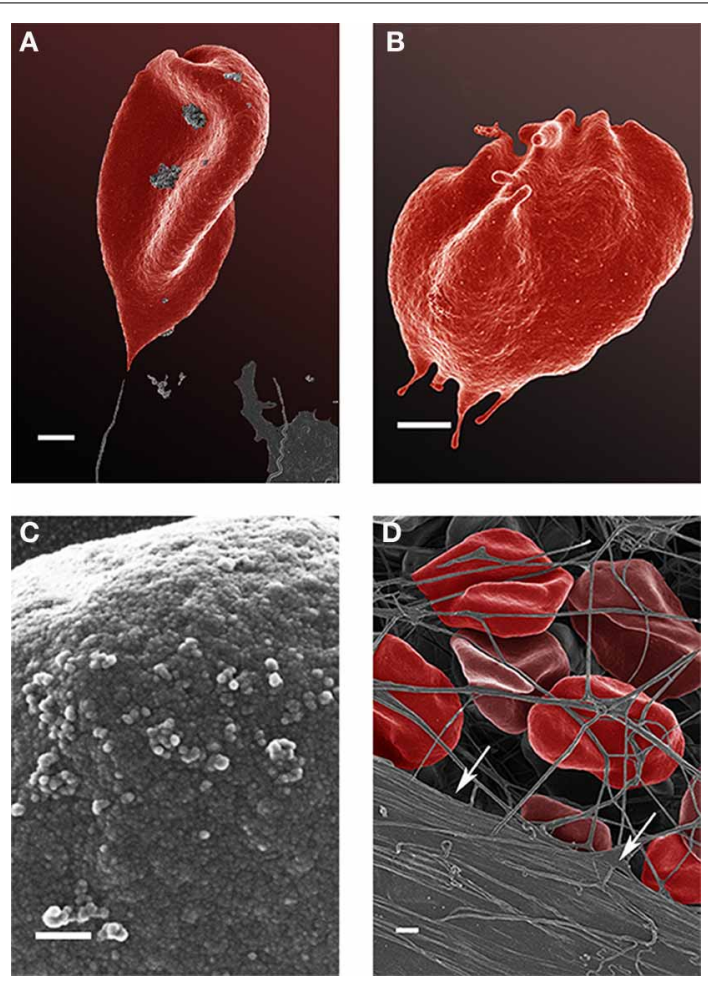

FIGURE 7 | Scanning electron microscopy (SEM) micrographs of a typical high serum ferritin (SF) Alzheimer's (AD) individual (scale $=1 \mu \mathrm{m})(\mathbf{A}, \mathbf{B})$. High machine magnification $(150,000 \times)$ of a typical RBC membrane from a high serum ferritin (SF) Alzheimer's (AD) individual (Scale $=100 \mathrm{~nm}$ ) (C); red blood cell from a high serum ferritin (SF) Alzheimer's (AD) individual where thrombin is added to whole blood; the cells loose their discoid shapes and dense matted fibrin deposits are present in the lower left corner of the micrograph (indicated by arrows) (scale $=1 \mu \mathrm{m}$ ) (D).

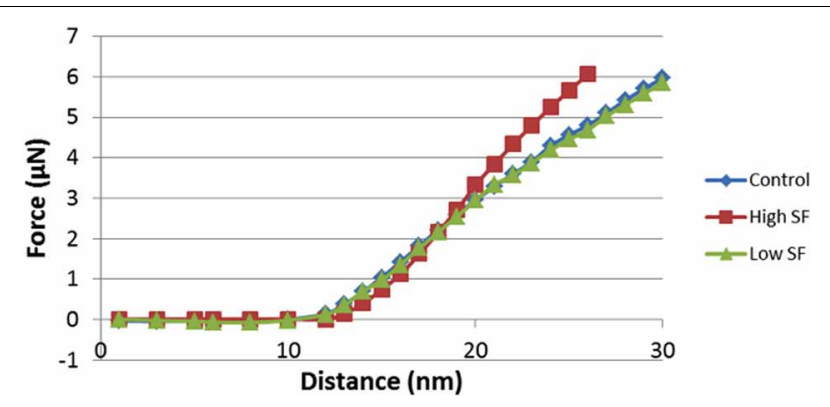

FIGURE 8 | Force-Distance curves obtained on RBCs from healthy individuals, normal serum ferritin (SF) Alzheimer's (AD) individuals and high serum ferritin (SF) Alzheimer's (AD) individuals.

Force-Distance curves show the atomic force microscope (AFM) cantilever deflection range on the platelet surface.

hemochromatosis, where iron overload is caused by a specific genetic mutation (Kwan et al., 1998; Shizukuda et al., 2006, 2007; Kell, 2009, 2010; Camaschella and Poggiali, 2011; Crichton et al., 2011; Castellani et al., 2012; Finberg, 2013; Funke et al., 2013; Martines et al., 2013; Pretorius et al., 2013a,c; Tsuchiya and Nitta,
2013). Many workers have suggested that increased iron levels are also associated with cardiovacular events by facilitating oxidative stress, and that iron-induced vascular dysfunction may contribute to the increased incidence of ischemic cardiovascular events (Corti et al., 1997; Horwitz and Rosenthal, 1999; Anderson et al., 2001; Day et al., 2003; Kondur et al., 2009; Zegrean, 2009; Zhao et al., 2010; Meroño et al., 2011; Zacharski et al., 2011; Rajapurkar et al., 2012). Poorly liganded iron is the main culprit and plays a fundamental role in the development of pathology (Kell, 2009, 2010). Moderate iron overload is also known to accelerate thrombus formation after arterial injury, increases vascular oxidative stress, and impairs vasoreactivity (Day et al., 2003). The main kind of mechanism by which iron overload causes tissue damage is considered to be free radical toxicity caused by the excessive levels of the (poorly liganded) metal (Jomova and Valko, 2011; Barton et al., 2012; Ferro et al., 2012; Pra et al., 2012; Crownover and Covey, 2013). Hydroxyl radicals ( $\mathrm{OH} \cdot$ ) are especially well-known culprits in causing damage to biomolecules, and iron catalyzes the redox-based production of hydroxyl radicals via the Fenton reaction (Goldstein et al., 1993; Wardman and Candeias, 1996; Aisen et al., 2001; Kell, 2009, 2010; Rival et al., 2009; Khechaduri et al., 2013).

Previously, we have shown that RBCs are very sensitive to unliganded iron changes, and that physiological levels of ferric iron, added to WB, cause shape changes in RBCs (Lipinski et al., 2012a; Pretorius and Lipinski, 2013). These shape changes are also present in hereditary hemochromatosis, as well as in cases of hyperferritinemia where the genetic mutation underpinning $\mathrm{HH}$ is not present (Pretorius et al., 2013a,b,c, in press). There are four iron measurements that medical practitioners typically will request when iron overload is suspected. They are SF, serum iron, serum transferrin and \% transferrin saturation (Brandhagen et al., 2002; Limdi and Crampton, 2004). Serum iron is the amount of circulating iron bound to transferrin; transferrin binds iron and controls the level of free iron in biological fluids. Optimal saturation should be between 20 and 45\% [\% transferrin binding sites that should be filled (McCullen et al., 2002; Limdi and Crampton, 2004; Daniels, 2010)]. We have indicated previously, that SF levels are the iron-related value that most effectively imply or reflect iron overload (Pretorius et al., 2013a,b,c, in press); and this view is reflected in the literature (Kellner and Zoller, 1992; Koziol et al., 2001; Adams et al., 2005, 2006; Adams, 2008; Jacobs et al., 2009; Gordeuk et al., 2012; Crownover and Covey, 2013)]. In the current study, we used SF levels as an indication of iron overload in our AD patient group. SF levels above approximately females $150 \mathrm{ng} / \mathrm{mL}^{-1}$ and males $300 \mathrm{ng} / \mathrm{mL}^{-1}$ was taken as implying iron overload (Kellner and Zoller, 1992; Koziol et al., 2001; Adams et al., 2005, 2006; Adams, 2008; Jacobs et al., 2009; Gordeuk et al., 2012; Crownover and Covey, 2013).

Inside cells, ferritin is the major iron storage protein, with 24 subunits forming a cage around up to 4500 iron atoms (Lu et al., 2013). However, the method of ferritin excretion into serum, and what it is that is secreted (just the protein shell subunits, or the entire ferritin molecule) that then degrades liberating iron, remains poorly understood. Ferritin concentrations in serum reflect the iron store of the body (Cook et al., 1974; Hori et al., 2010). Although ferritin itself may protect against oxidative stress 

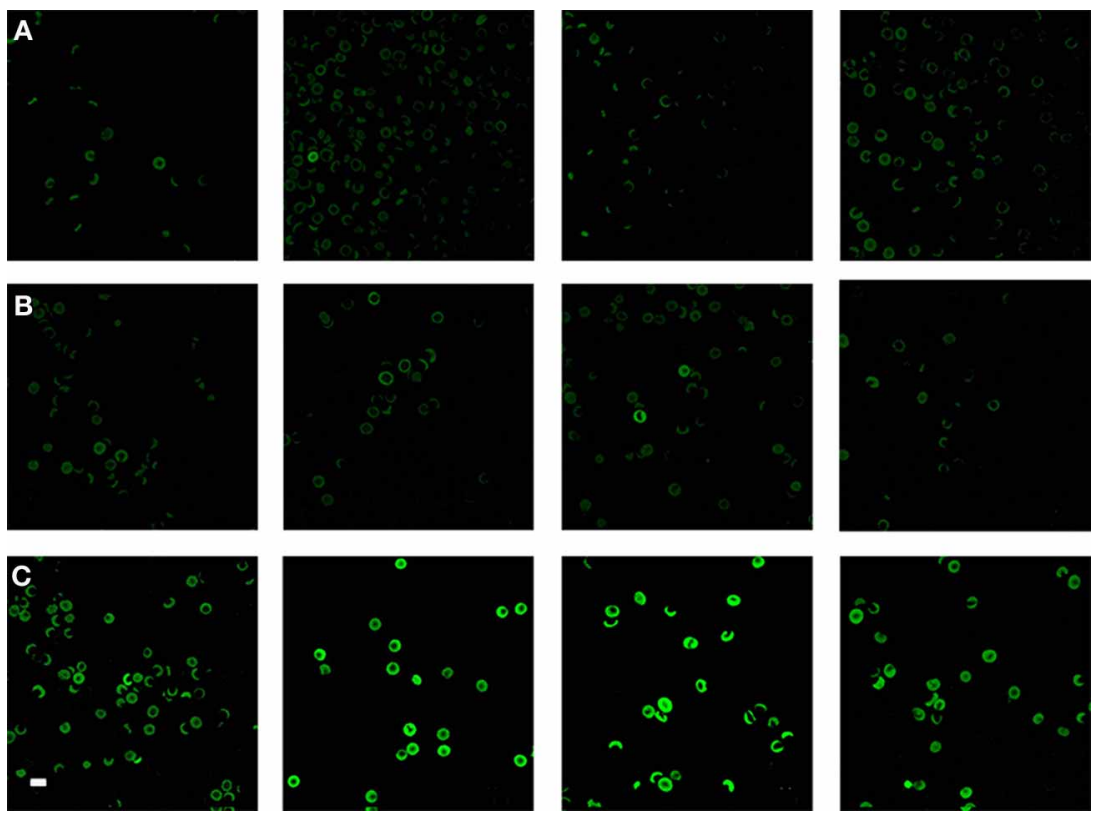

FIGURE 9 | Confocal microscopy of RBCs from (A) four healthy individuals, (B) four normal serum ferritin (SF) Alzheimer's individuals (AD) and (C) four high SF AD individuals. Scale $=10 \mu \mathrm{m}$.

Table 4 | Alzheimer's disease patient data, showing duration and age of onset and serum ferritin (SF) levels, as well as severity of changes, indicated as normal discoid morphology, slightly affected and severely affected shape changes.

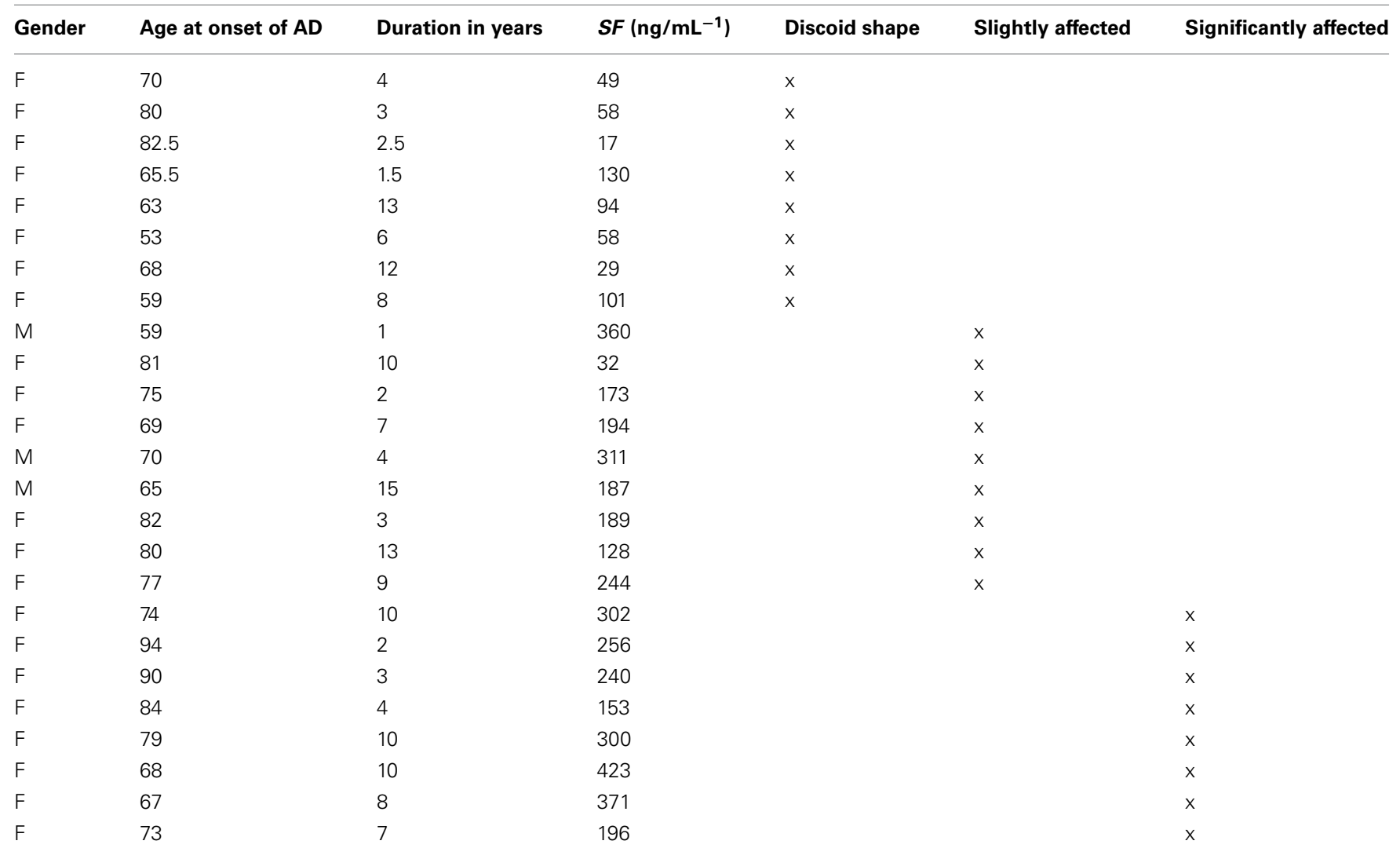




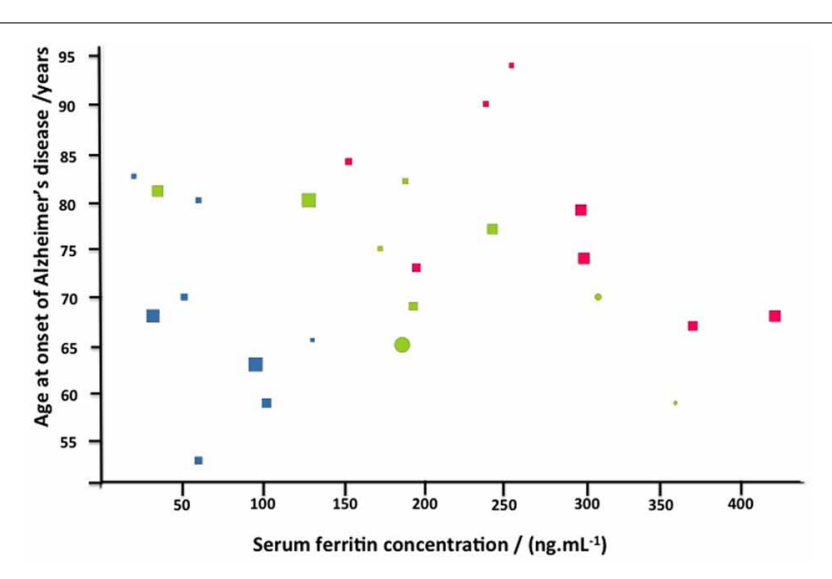

FIGURE 10 | Alzheimer's disease as a function of serum ferritin for normal (blue) slightly (green) or strongly affected (red) morphologies. Also displayed are gender (females circles, males squares), and duration in years (via the size of the symbols).

by chelating free iron (Torti and Torti, 2002), it can also be a mediator of oxidative stress by releasing free iron (Reif, 1992). Thus, despite its clear usefulness as a clinical tool to assess body iron stores, much of the pathophysiology of SF remains vague. We have, however, come to the conclusion that SF is a good biomarker, as it is widely used in diagnosing and monitoring iron overload diseases (Adams, 2008; Wang et al., 2010). This would be consistent with a view that the levels of SF do reflect unliganded iron that has been liberated during or following its secretion.

Where high SF levels are present in the $\mathrm{AD}$ individuals, and when thrombin is added to $\mathrm{WB}$, the RBCs deform and twist around the resulting fibrin fibers (Figure 6D). In the current study we compared RBCs of AD individuals with normal and high SF levels to RBCs taken from healthy individuals. Interestingly, we found that RBCs from the normal SF AD individuals still keep their discoid shape. Also, when thrombin is added to WB, the cells still appear discoid when entrapped in the resulting fibrin fiber network. However, when we study RBCs from high SF AD individuals, their RBCs have a somewhat more elongated shape. This is seen in LM, as well as SEM micrographs (Figures 2, 3).

We also confirm previous results that suggest that fibrin is altered in $\mathrm{AD}$ and it was also shown that fibrin interacts with beta-amyloid protein (Merkle et al., 1996; Choi et al., 2002). Also, literature suggests that fibrinogen can bind iron (Orino, 2013) and that this might be pertinent to the correlation between high ferritin and aberrant fibrin morphology as seen in Figure 7D.

We confirmed that high SF AD RBCs have an increased Young's modulus, and therefore decreased elasticity as seen from the AFM results. This finding is in line with previous research that reported increased Young's modulus values in pathological RBCs (Dulinska et al., 2006) and living cells (Müller et al., 2009). Although the cells in the aforementioned study were only briefly fixed and followed by analysis in fluid, other studies have shown that variances in elasticity of different types of dried Jurkat cells (Cai et al., 2009) and RBCs (Jin et al., 2010; Dufrêne et al., 2013; Picas et al., 2013) can be detected. We suggest that the RBC deformability in $\mathrm{AD}$ with high SF levels may be due to membrane and cytoskeletal architectural changes and that this might be the reason why the cells have lost their ability to maintain or return to their discoid shape in the presence of fibrin fibers. Continuous and unobstructed delivery of oxygen to the brain via the RBCs, depends on their membrane fluidity (Tateishi et al., 2001). RBCs are highly deformable and elastic, and this physical property contributes significantly to aiding blood flow in the microcirculation (Baskurt and Meiselman, 2003; Mohandas and Gallagher, 2008). Furthermore, research suggests that blood rheology is altered in various pathophysiological conditions. The extent of deformability may be affected by, amongst others, alterations of the properties and associations of membrane skeletal proteins (Koshino et al., 2012). If RBCs have optimal functioning, their ability to deform improves blood flow in the micro-vessels at high shear rate (Shin et al., 2007), and membrane architecture also plays an important role in the mechanical stability of the cells in the presence of shear forces (Nans et al., 2011). Baines in 2009 suggested that the elasticity of RBCs depends on the dynamic rearrangement of spectrin dimers/tetramers under the shearing forces experienced in circulation (Baines, 2009); and that stable intact helical linker regions are needed to maintain the soft elasticity of spectrin (Mirijanian and Voth, 2008). A decreased deformability is also seen in inflammatory conditions such as diabetes (Shin et al., 2007); a spatial reorganization of the cytoskeleton was also noted in this condition (Starodubtseva et al., 2008). A reduced plasticity in cerebral ischemia (Kowal, 1996) and increase stiffness was also noted in conditions like coronary disease and hypertension (Lekka et al., 2005). It therefore seems as if a decreased deformability and increase in stiffness is common in inflammatory disease, and can be ascribed to a changed elasticity as well as stability. Therefore, the changed elasticity seen in the current study, will impact on the membrane fluidity and deformability of the cell as it moves through the circulation. This may result in atypical tissue perfusion, leading to functional deteriorations, ultimately resulting in disturbed vascular properties (Baskurt and Meiselman, 2003). Confocal microscopy confirmed that RBCs from high SF AD individuals have structural membrane damage, in that the probe assessed enters the cell membrane and binds to the amines inside the cell, causing a bright fluorescence in the cells of this group. The bright fluorescence was present to a much lesser degree in RBCs taken from the normal SF AD individuals or the controls, and here only a dull fluorescence was seen, suggesting that as expected the dye reacts only with to the amines on the outer membrane. Statistical analyses confirmed that there was a significant difference between the CTCF of RBCs from healthy and high SF AD individuals, while there were no significant difference between the CTCF of RBCs from healthy individuals vs. normal SF AD individuals. Grading of the severity of the changes (Table 4 and Figure 10), confirms that the SF levels are well correlated with the severity of the RBC shape changes.

\section{CONCLUSION}

Despite many years of $\mathrm{AD}$ research, we still do not know the best strategies to treat this very debilitating condition, and its likely multifactorial aetiology could be taken to suggest that we 
need a multi-modal treatment regime [e.g., (Kupershmidt et al., $2012 \mathrm{a})]$. In the current study we were surprised to find that $60 \%$ of our randomly chosen $\mathrm{AD}$ population had increased SF levels. Although we have shown in the introductory paragraphs that there is extensive literature suggesting that iron levels have been closely associated with AD pathology and might exacerbate pathology in these patients (see above), iron levels in AD patients are not seen as a compulsory pathology test (personal communications with neurologists treating AD patients), notwithstanding literature indicating the relevance of ferritin dysregulation to AD [e.g., (Connor et al., 1992; Quintana et al., 2006; Friedman et al., 2011; Giambattistelli et al., 2012; De Sole et al., 2013)]. Importantly, our findings support the literature regarding dysregulated iron metabolism, as $60 \%$ of our sample shows high SF levels. We show that RBC ultrastructure is changed significantly in the presence of iron overload (as judged by SF). We have demonstrated this with 4 different techniques and statistical analysis confirms this. These changes might impair the oxygen carrying capacity and compromise hemorheology of the RBCs, and additionally cause a strain on the already challenged brain function of these individuals. It seems as if iron overload might be present in $\mathrm{AD}$ patients more widely than generally believed. Indeed, iron overload might cause the condition to progress faster than in $\mathrm{AD}$ individuals who do not have iron overload, particularly due to the additional hydroxyl radical load. The substantial differences in the RBCs, of high-SF AD patients might suggest that some of the minimally invasive measurements we have performed might be of diagnostic significance, while the potential for chelating or liganding iron might have some therapeutic benefits [as first shown more than 20 years ago (Crapper McLachlan et al., 1991) and more recently (Kupershmidt et al., 2012b)]. We conclude by recommending that $\mathrm{AD}$ patients should be screened for iron overload and that, when it is present, a comprehensive treatment regime be implemented to monitor and indeed decrease iron levels throughout the progression of this very debilitating condition.

\section{AUTHOR CONTRIBUTIONS}

Janette Bester Collecting of samples, preparation of samples, SEM, LM, and confocal analysis Antoinette V. Buys AFM analysis Boguslaw Lipinski research idea and manuscript preparation Douglas B. Kell statistical analysis, manuscript preparation. Etheresia Pretorius study leader, SEM and AFM analysis manuscript preparation.

\section{ETHICAL CLEARANCE AND CONSENT}

Ethical clearance was obtained from the Health Sciences Ethical committee from the University of Pretoria and informed consent was obtained from family members who act as guardians of the patients. Healthy individuals also filled in consent forms.

\section{ACKNOWLEDGMENTS}

We would like to acknowledge Dr Prashilla Soma who drew our blood samples and Dr Wiebren Duim (Neurologist) who gave us insights regarding the Alzheimer's patient sample. Also, we are in debt to the family members of the patients who gave informed consent for the study. We thank an anonymous referee for an extremely helpful suggestion that led to the analyses given in Table 4 and Figure 10.

\section{FUNDING}

Funding body: The National Research Foundation of South Africa (NRF): E Pretorius. The funder had no role in study design, data collection and analysis, decision to publish, or preparation of the manuscript.

\section{REFERENCES}

Adams, P. (2008). Management of elevated serum ferritin levels. Gastroenterol. Hepatol. (N.Y.) 4, 333-334.

Adams, P. C., Passmore, L., Chakrabarti, S., Reboussin, D. M., Acton, R. T., Barton, J. C., et al. (2006). Liver diseases in the hemochromatosis and iron overload screening study. Clin. Gastroenterol. Hepatol. 4, 918-923; quiz 807. doi: 10.1016/j.cgh.2006.04.013

Adams, P. C., Reboussin, D. M., Barton, J. C., McLaren, C. E., Eckfeldt, J. H., McLaren, G. D., et al. (2005). Hemochromatosis and iron-overload screening in a racially diverse population. N. Engl. J. Med. 352, 1769-1778. doi: 10.1056/NEJMoa041534

Aisen, P., Enns, C., and Wessling-Resnick, M. (2001). Chemistry and biology of eukaryotic iron metabolism. Int. J. Biochem. Cell Biol. 33, 940-959. doi: 10.1016/S1357-2725(01)00063-2

Anderson, L. J., Holden, S., Davis, B., Prescott, E., Charrier, C. C., Bunce, N. H., et al. (2001). Cardiovascular T2-star $\left(\mathrm{T} 2^{\star}\right)$ magnetic resonance for the early diagnosis of myocardial iron overload. Eur. Heart J. 22, 2171-2179. doi: 10.1053/euhj.2001.2822

Andresdottir, M. B., Sigfusson, N., Sigvaldason, H., and Gudnason, V. (2003). Erythrocyte sedimentation rate, an independent predictor of coronary heart disease in men and women: the Reykjavik Study. Am. J. Epidemiol. 158, 844-851. doi: 10.1093/aje/kwg222

Baines, A. J. (2009). Evolution of spectrin function in cytoskeletal and membrane networks. Biochem. Soc. Trans. 37, 796-803. doi: 10.1042/BST0370796

Barnham, K. J., and Bush, A. I. (2008). Metals in Alzheimer's and Parkinson's diseases. Curr. Opin. Chem. Biol. 12, 222-228. doi: 10.1016/j.cbpa.2008.02.019

Barton, J. C., Barton, J. C., Acton, R. T., So, J., Chan, S., and Adams, P. C. (2012). Increased risk of death from iron overload among 422 treated probands with HFE hemochromatosis and serum levels of ferritin greater than $1000 \mathrm{mug} / \mathrm{L}$ at diagnosis. Clin. Gastroenterol. Hepatol. 10, 412-416. doi: 10.1016/j.cgh.2011.11.032

Bartzokis, G., Lu, P. H., Tingus, K., Peters, D. G., Amar, C. P., Tishler, T. A., et al. (2011). Gender and iron genes may modify associations between brain iron and memory in healthy aging. Neuropsychopharmacology 36, 1375-1384. doi: $10.1038 / \mathrm{npp} .2011 .22$

Baskurt, O. K., and Meiselman, H. J. (2003). Blood rheology and hemodynamics. Semin. Thromb. Hemost. 29, 435-450. doi: 10.1055/s-2003-44551

Berquand, A. (2011). Quantitative imaging of living biological samples by PeakForce QNM atomic force microscopy. Bruker Application Note 135, 1-10.

Brandhagen, D. J., Fairbanks, V. F., and Baldus, W. (2002). Recognition and management of hereditary hemochromatosis. Am. Fam. Physician 65, 853-860.

Broadhurst, D., and Kell, D. B. (2006). Statistical strategies for avoiding false discoveries in metabolomics and related experiments. Metabolomics 2, 171-196. doi: 10.1007/s11306-006-0037-z

Buys, A. V., Van Rooy, M. J., Soma, P., Van Papendorp, D., Lipinski, B., and Pretorius, E. (2013). Changes in red blood cell membrane structure in type 2 diabetes: a scanning electron and atomic force microscopy study. Cardiovasc. Diabetol. 12:25. doi: 10.1186/1475-2840-12-25

Cai, X., Gao, S., Cai, J., Wu, Y., and Deng, H. (2009). Artesunate induced morphological and mechanical changes of Jurkat cell studied by AFM. Scanning 31, 83-89. doi: 10.1002/sca.20144

Camaschella, C., and Poggiali, E. (2011). Inherited disorders of iron metabolism. Curr. Opin. Pediatr. 23, 14-20. doi: 10.1097/MOP.0b013e3283425591

Carpenter, J. P., Grasso, A. E., Porter, J. B., Shah, F., Dooley, J., and Pennell, D. J. (2013). On myocardial siderosis and left ventricular dysfunction in hemochromatosis. J. Cardiovasc. Magn. Reson. 15:24. doi: 10.1186/1532-429X-15-24 
Casadesus, G., Smith, M. A., Zhu, X., Aliev, G., Cash, A. D., Honda, K., et al. (2004). Alzheimer disease: evidence for a central pathogenic role of iron-mediated reactive oxygen species. J. Alzheimers Dis. 6, 165-169.

Castellani, R. J., Moreira, P. I., Perry, G., and Zhu, X. (2012). The role of iron as a mediator of oxidative stress in Alzheimer disease. Biofactors 38, 133-138. doi: 10.1002/biof.1010

Choi, J., Malakowsky, C. A., Talent, J. M., Conrad, C. C., and Gracy, R. W. (2002). Identification of oxidized plasma proteins in Alzheimer's disease. Biochem. Biophys. Res. Commun. 293, 1566-1570. doi: 10.1016/S0006-291X(02) 00420-5

Connor, J. R., Menzies, S. L., St Martin, S. M., and Mufson, E. J. (1992). A histochemical study of iron, transferrin, and ferritin in Alzheimer's diseased brains. J. Neurosci. Res. 31, 75-83. doi: 10.1002/jnr.490310111

Cook, J. D., Lipschitz, D. A., Miles, L. E., and Finch, C. A. (1974). Serum ferritin as a measure of iron stores in normal subjects. Am. J. Clin. Nutr. 27, 681-687.

Copenhaver, W. M., Bunge, R. P., and Bunge, M. B. (1971). Bailey's Textbook of Histology. Baltimore: The Williams and Wilkins Company.

Corti, M. C., Gaziano, M., and Hennekens, C. H. (1997). Iron status and risk of cardiovascular disease. Ann. Epidemiol. 7, 62-68. doi: 10.1016/S10472797(96)00112-3

Crapper McLachlan, D. R., Dalton, A. J., Kruck, T. P., Bell, M. Y., Smith, W. L., Kalow, W., et al. (1991). Intramuscular desferrioxamine in patients with Alzheimer's disease. Lancet 337, 1304-1308. doi: 10.1016/0140-6736(91) 92978-B

Crichton, R. R., Dexter, D. T., and Ward, R. J. (2011). Brain iron metabolism and its perturbation in neurological diseases. J. Neural Transm. 118, 301-314. doi: 10.1007/s00702-010-0470-z

Crownover, B. K., and Covey, C. J. (2013). Hereditary hemochromatosis. Am. Fam. Physician 87, 183-190.

Daniels, R. (2010). Delmar's Guide to Laboratory and Diagnostic Tests. 2nd Edn. New York, NY: Clifton Park.

Davalos, D., and Akassoglou, K. (2012). Fibrinogen as a key regulator of inflammation in disease. Semin. Immunopathol. 34, 43-62. doi: 10.1007/s00281-0110290-8

Day, S. M., Duquaine, D., Mundada, L. V., Menon, R. G., Khan, B. V., Rajagopalan, S., et al. (2003). Chronic iron administration increases vascular oxidative stress and accelerates arterial thrombosis. Circulation 107, 2601-2606. doi: 10.1161/01.CIR.0000066910.02844.D0

Derjaguin, B., Muller, V., and Toporov, Y. (1975). Effect of contact deformations on the adhesion of particles. J. Colloid Interf. Sci. 53, 314-326. doi: 10.1016/00219797(75)90018-1

De Sole, P., Rossi, C., Chiarpotto, M., Ciasca, G., Bocca, B., Alimonti, A., et al. (2013). Possible relationship between Al/ferritin complex and Alzheimer's disease. Clin. Biochem. 46, 89-93. doi: 10.1016/j.clinbiochem. 2012.10.023

Diomedi, M., and Misaggi, G. (2013). Vascular contribution to Alzheimer disease: predictors of rapid progression. CNS Neurol. Disord. Drug Targets 12, 532-537. doi: 10.2174/1871527311312040015

Dufrêne, Y. F., Martínez-Martin, D., Medalsy, I., Alsteens, D., and Müller, D. J. (2013). Multiparametric imaging of biological systems by force-distance curve-based AFM. Nat. Methods 10, 847-854. doi: 10.1038/nmeth.2602

Dulinska, I., Targosz, M., Strojny, W., Lekka, M., Czuba, P., Balwierz, W., et al. (2006). Stiffness of normal and pathological erythrocytes studied by means of atomic force microscopy. J. Biochem. Biophys. Methods 66, 1-11. doi: 10.1016/j.jbbm.2005.11.003

Eltzschig, H. K., and Carmeliet, P. (2011). Hypoxia and inflammation. N. Engl. J. Med. 364, 656-665. doi: 10.1056/NEJMra0910283

Ershova, L. I., Likhovetskaia, Z. M., Kurbanova, G. N., Shcherbinina, S. P., and Gorbunova, N. A. (1998). Pathogenetic aspects of hemolysis and changes of blood rheology in hereditary hemochromatosis. Ter. Arkh. 70, 74-76.

Ferro, E., Visalli, G., Civa, R., La Rosa, M. A., Randazzo Papa, G., Baluce, B., et al. (2012). Oxidative damage and genotoxicity biomarkers in transfused and untransfused thalassemic subjects. Free Radic. Biol. Med. 53, 1829-1837. doi: 10.1016/j.freeradbiomed.2012.08.592

Finberg, K. E. (2013). Striking the target in iron overload disorders. J. Clin. Invest. 123, 1424-1427. doi: 10.1172/JCI68889

Friedman, A., Arosio, P., Finazzi, D., Koziorowski, D., and Galazka-Friedman, J. (2011). Ferritin as an important player in neurodegeneration. Parkinsonism Relat. Disord. 17, 423-430. doi: 10.1016/j.parkreldis.2011.03.016
Funke, C., Schneider, S. A., Berg, D., and Kell, D. B. (2013). Genetics and iron in the systems biology of Parkinson's disease and some related disorders. Neurochem. Int. 62, 637-652. doi: 10.1016/j.neuint.2012.11.015

Giambattistelli, F., Bucossi, S., Salustri, C., Panetta, V., Mariani, S., Siotto, M., et al. (2012). Effects of hemochromatosis and transferrin gene mutations on iron dyshomeostasis, liver dysfunction and on the risk of Alzheimer's disease. Neurobiol. Aging 33, 1633-1641. doi: 10.1016/j.neurobiolaging.2011.03.005

Goldstein, S., Meyerstein, D., and Czapski, G. (1993). The Fenton reagents. Free Radic. Biol. Med. 15, 435-445. doi: 10.1016/0891-5849(93)90043-T

Gordeuk, V. R., Lovato, L., Barton, J., Vitolins, M., McLaren, G., Acton, R., et al. (2012). Dietary iron intake and serum ferritin concentration in 213 patients homozygous for the HFEC282Y hemochromatosis mutation. Can. J. Gastroenterol. 26, 345-349.

Hori, A., Mizoue, T., Kasai, H., Kawai, K., Matsushita, Y., Nanri, A., et al. (2010) Body iron store as a predictor of oxidative DNA damage in healthy men and women. Cancer Sci. 101, 517-522. doi: 10.1111/j.1349-7006.2009.01394.x

Horwitz, L. D., and Rosenthal, E. A. (1999). Iron-mediated cardiovascular injury. Vasc. Med. 4, 93-99. doi: 10.1191/135886399676588477

Jacobs, E. M., Hendriks, J. C., van Deursen, C. T., Kreeftenberg, H. G., de Vries, R. A., Marx, J. J., et al. (2009). Severity of iron overload of proband determines serum ferritin levels in families with HFE-related hemochromatosis: the HEmochromatosis FAmily Study. J. Hepatol. 50, 174-183. doi: 10.1016/j.jhep.2008.08.014

Jin, H., Xing, X., Zhao, H., Chen, Y., Huang, X., Ma, S., et al. (2010). Detection of erythrocytes influenced by aging and type 2 diabetes using atomic force microscope. Biochem. Biophys. Res. Commun. 391, 1698-1702. doi: 10.1016/j.bbrc.2009.12.133

Jomova, K., and Valko, M. (2011). Importance of iron chelation in free radicalinduced oxidative stress and human disease. Curr. Pharm. Des. 17, 3460-3473. doi: $10.2174 / 138161211798072463$

Kanwar, P., and Kowdley, K. V. (2013). Diagnosis and treatment of hereditary hemochromatosis: an update. Expert Rev. Gastroenterol. Hepatol. 7, 517-530. doi: 10.1586/17474124.2013.816114

Kell, D. B. (2009). Iron behaving badly: inappropriate iron chelation as a major contributor to the aetiology of vascular and other progressive inflammatory and degenerative diseases. BMC Med. Genomics 2:2. doi: 10.1186/1755-8794-2-2

Kell, D. B. (2010). Towards a unifying, systems biology understanding of largescale cellular death and destruction caused by poorly liganded iron: Parkinson's, Huntington's, Alzheimer's, prions, bactericides, chemical toxicology and others as examples. Arch. Toxicol. 84, 825-889. doi: 10.1007/s00204-010-0577-x

Kellner, H., and Zoller, W. G. (1992). Repeated isovolemic large-volume erythrocytapheresis in the treatment of idiopathic hemochromatosis. Z. Gastroenterol. 30, 779-783.

Khechaduri, A., Bayeva, M., Chang, H. C., and Ardehali, H. (2013). Heme levels are increased in human failing hearts. J. Am. Coll. Cardiol. 61, 1884-1893. doi: 10.1016/j.jacc.2013.02.012

Kling, M. A., Trojanowski, J. Q., Wolk, D. A., Lee, V. M. A., and Arnold, S. E. (2013). Vascular disease and dementias: paradigm shifts to drive research in new directions. Alzheimers Dement 9, 76-92. doi: 10.1016/j.jalz. 2012.02.007

Kolar, P., Tomankova, K., Malohlava, J., Zapletalova, J., Vujtek, M., Safarova, K. et al. (2013). The effect of photodynamic treatment on the morphological and mechanical properties of the HeLa cell line. Gen. Physiol. Biophys. 32, 337-346. doi: $10.4149 / \mathrm{gpb} 2013042$

Kondur, A. K., Li, T., Vaitkevicius, P., and Afonso, L. (2009). Quantification of myocardial iron overload by cardiovascular magnetic resonance imaging $\mathrm{T} 2 *$ and review of the literature. Clin. Cardiol. 32, E55-E59. doi: 10.1002/clc.20310

Koshino, I., Mohandas, N., and Takakuwa, Y. (2012). Identification of a novel role for dematin in regulating red cell membrane function by modulating spectrin-actin interaction. J. Biol. Chem. 287, 35244-35250. doi: 10.1074/jbc.M111.305441

Kovacic, J. C., and Fuster, V. (2012). Atherosclerotic risk factors, vascular cognitive impairment, and Alzheimer disease. Mt. Sinai J. Med. 79, 664-673. doi: $10.1002 / \mathrm{msj} .21347$

Kowal, P. (1996). Hemorheology in cerebral ischemia. Neurol. Neurochir. Pol. 30(Suppl. 2), 7-11.

Koziol, J. A., Ho, N. J., Felitti, V. J., and Beutler, E. (2001). Reference centiles for serum ferritin and percentage of transferrin saturation, with application to mutations of the HFE gene. Clin. Chem. 47, 1804-1810. 
Kupershmidt, L., Amit, T., Bar-Am, O., Weinreb, O., and Youdim, M. B. (2012a). Multi-target, neuroprotective and neurorestorative M30 improves cognitive impairment and reduces Alzheimer's-like neuropathology and age-related alterations in mice. Mol. Neurobiol. 46, 217-220. doi: 10.1007/s12035-012-8304-7

Kupershmidt, L., Amit, T., Bar-Am, O., Youdim, M. B., and Weinreb, O. (2012b). The novel multi-target iron chelating-radical scavenging compound M30 possesses beneficial effects on major hallmarks of Alzheimer's disease. Antioxid. Redox Signal. 17, 860-877. doi: 10.1089/ars.2011.4279

Kwan, T., Leber, B., Ahuja, S., Carter, R., and Gerstein, H. C. (1998). Patients with type 2 diabetes have a high frequency of the C282Y mutation of the hemochromatosis gene. Clin. Invest. Med. 21, 251-257.

Lekka, M., Fornal, M., Pyka-Fosciak, G., Lebed, K., Wizner, B., Grodzicki, T., et al. (2005). Erythrocyte stiffness probed using atomic force microscope. Biorheology 42, 307-317.

Limdi, J. K., and Crampton, J. R. (2004). Hereditary haemochromatosis. QJM 97, 315-324. doi: 10.1093/qjmed/hch065

Lipinski, B., and Pretorius, E. (2013). Iron-induced fibrin in cardiovascular disease. Curr. Neurovasc. Res. 10, 269-274. doi: 10.2174/15672026113109990016

Lipinski, B., Pretorius, E., Oberholzer, H. M., and van der Spuy, W. J. (2012a). Interaction of fibrin with red blood cells: the role of iron. Ultrastruct. Pathol. 36, 79-84. doi: 10.3109/01913123.2011.627491

Lipinski, B., Pretorius, E., Oberholzer, H. M., and van der Spuy, W. J. (2012b). Iron enhances generation of fibrin fibers in human blood: implications for pathogenesis of stroke. Microsc. Res. Tech. 75, 1185-1190. doi: 10.1002/jemt.22047

Lu, X., Wu, L., Liu, Z., Xie, L., and Wang, S. (2013). Peripheral blood mononuclear cells inhibit proliferation and promote apoptosis of HeLa cells following stimulation with Bacillus Calmette-Guerin. Exp. Ther. Med. 5, 561-566.

Maggio, A., Vitrano, A., Calvaruso, G., Barone, R., Rigano, P., Mancuso, L., et al. (2013). Serial echocardiographic left ventricular ejection fraction measurements: a tool for detecting thalassemia major patients at risk of cardiac death. Blood Cells Mol. Dis. 50, 241-246. doi: 10.1016/j.bcmd.2012.12.002

Martines, A. M. F., Masereeuw, R., Tjalsma, H., Hoenderop, J. G., Wetzels, J. F. M., and Swinkels, D. W. (2013). Iron metabolism in the pathogenesis of iron-induced kidney injury. Nat. Rev. Nephrol. 9, 385-398. doi: 10.1038/nrneph.2013.98

McCullen, M. A., Crawford, D. H., and Hickman, P. E. (2002). Screening for hemochromatosis. Clin. Chim. Acta 315, 169-186. doi: 10.1016/S00098981(01)00711-2

McMahon, C. J., Hopkins, S., Vail, A., King, A. T., Smith, D., Illingworth, K. J. et al. (2013). Inflammation as a predictor for delayed cerebral ischemia after aneurysmal subarachnoid haemorrhage. J. Neurointerv. Surg. 5, 512-517. doi: 10.1136/neurintsurg-2012-010386

Merkle, D. L., Cheng, C. H., Castellino, F. J., and Chibber, B. A. (1996). Modulation of fibrin assembly and polymerization by the beta-amyloid of Alzheimer's disease. Blood Coagul. Fibrinolysis 7, 650-658. doi: 10.1097/00001721-19960900000011

Meroño, T., Rosso, L. G., Sorroche, P., Boero, L., Arbelbide, J., and Brites, F. (2011). High risk of cardiovascular disease in iron overload patients. Eur. J. Clin. Invest. 41, 479-486. doi: 10.1111/j.1365-2362.2010.02429.x

Mirijanian, D. T., and Voth, G. A. (2008). Unique elastic properties of the spectrin tetramer as revealed by multiscale coarse-grained modeling. Proc. Natl. Acad. Sci. U.S.A. 105, 1204-1208. doi: 10.1073/pnas.0707500105

Mohandas, N., and Gallagher, P. G. (2008). Red cell membrane: past, present, and future. Blood 112, 3939-3948. doi: 10.1182/blood-2008-07-161166

Mohanty, J. G., Eckley, D. M., Williamson, J. D., Launer, L. J., and Rifkind, J. M. (2008). Do red blood cell-beta-amyloid interactions alter oxygen delivery in Alzheimer's disease? Adv. Exp. Med. Biol. 614, 29-35. doi: 10.1007/978-0-38774911-2_4

Mohanty, J. G., Shukla, H. D., Williamson, J. D., Launer, L. J., Saxena, S., and Rifkind, J. M. (2010). Alterations in the red blood cell membrane proteome in alzheimer's subjects reflect disease-related changes and provide insight into altered cell morphology. Proteome Sci. 8, 11. doi: 10.1186/1477-5956-8-11

Müller, D. J., Helenius, J., Alsteens, D., and Dufreñe, Y. F. (2009). Force probing surfaces of living cells to molecular resolution. Nat. Chem. Biol. 5, 383-390. doi: $10.1038 /$ nchembio. 181

Nans, A., Mohandas, N., and Stokes, D. L. (2011). Native ultrastructure of the red cell cytoskeleton by cryo-electron tomography. Biophys. J. 101, 2341-2350. doi: 10.1016/j.bpj.2011.09.050
Noori, N. M., Keshavarz, K., and Shahriar, M. (2012). Cardiac and pulmonary dysfunction in asymptomatic beta-thalassanemia major. Asian Cardiovasc. Thorac. Ann. 20, 555-559. doi: 10.1177/0218492312439706

Orino, K. (2013). Functional binding analysis of human fibrinogen as an iron- and heme-binding protein. Biometals 26, 789-794. doi: 10.1007/s10534-013-9657-8

Paul, J., Strickland, S., and Melchor, J. P. (2007). Fibrin deposition accelerates neurovascular damage and neuroinflammation in mouse models of Alzheimer's disease. J. Exp. Med. 204, 1999-2008. doi: 10.1084/jem.20070304

Penke, L., Valdés Hernandéz, M. C., Maniega, S. M., Gow, A. J., Murray, C., Starr, J. M., et al. (2012). Brain iron deposits are associated with general cognitive ability and cognitive aging. Neurobiol. Aging 33, 510-517 e512. doi: 10.1016/j.neurobiolaging.2010.04.032

Perfetto, S. P., Chattopadhyay, P. K., Lamoreaux, L., Nguyen, R., Ambrozak, D., Koup, R. A., et al. (2010). Amine-reactive dyes for dead cell discrimination in fixed samples. Curr. Protoc. Cytom. Chapter 9, Unit 9.34. doi: 10.1002/0471142956.cy0934s53

Picas, L., Rico, F., Deforet, M., and Scheuring, S. (2013). Structural and mechanical heterogeneity of the erythrocyte membrane reveals hallmarks of membrane stability. ACS Nano 7, 1054-1063. doi: 10.1021/nn303824j

Pra, D., Franke, S. I., Henriques, J. A., and Fenech, M. (2012). Iron and genome stability: an update. Mutat. Res. 733, 92-99. doi: 10.1016/j.mrfmmm.2012.02.001

Pretorius, E. (2013). The adaptability of red blood cells. Cardiovasc. Diabetol. 12:63. doi: 10.1186/1475-2840-12-63

Pretorius, E., Bester, J., Vermeulen, N., and Lipinski, B. (2013a). Oxidation inhibits iron-induced blood coagulation. Curr. Drug Targets 14, 13-19. doi: $10.2174 / 138945013804806541$

Pretorius, E., du Plooy, J. N., Soma, P., Keyser, I., and Buys, A. V. (2013b). Smoking and fluidity of erythrocyte membranes: a high resolution scanning electron and atomic force microscopy investigation. Nitric oxide 35C, 42-46. doi: 10.1016/j. niox.2013.08.003

Pretorius, E., Vermeulen, N., Bester, J., Lipinski, B., and Kell, D. B. (2013c). A novel method for assessing the role of iron and its functional chelation in fibrin fibril formation: the use of scanning electron microscopy. Toxicol. Mech. Methods 23, 352-359. doi: 10.3109/15376516.2012.762082

Pretorius, E., Bester, J., Vermeulen, N., Lipinski, B., Gericke, G. S., and Kell, D. B. (in press). Profound morphological changes in the erythrocytes and fibrin networks of patients with hemochromatosis or with hyperferritinemia, and their normalization by iron chelators and other agents. PLOS ONE

Pretorius, E., and Lipinski, B. (2013). Iron alters red blood cell morphology. Blood 121, 9. doi: 10.1182/blood-2012-09-454793

Quintana, C., Bellefqih, S., Laval, J. Y., Guerquin-Kern, J. L., Wu, T. D., Avila, J., et al. (2006). Study of the localization of iron, ferritin, and hemosiderin in Alzheimer's disease hippocampus by analytical microscopy at the subcellular level. J. Struct. Biol. 153, 42-54. doi: 10.1016/j.jsb.2005.11.001

Rajapurkar, M. M., Shah, S. V., Lele, S. S., Hegde, U. N., Lensing, S. Y., Gohel, K., et al. (2012). Association of catalytic iron with cardiovascular disease. Am. J. Cardiol. 109, 438-442. doi: 10.1016/j.amjcard.2011.09.032

Reif, D. W. (1992). Ferritin as a source of iron for oxidative damage. Free Radic. Biol. Med. 12, 417-427. doi: 10.1016/0891-5849(92)90091-T

Rival, T., Page, R. M., Chandraratna, D. S., Sendall, T. J., Ryder, E., Liu, B., et al. (2009). Fenton chemistry and oxidative stress mediate the toxicity of the betaamyloid peptide in a Drosophila model of Alzheimer's disease. Eur. J. Neurosci. 29, 1335-1347. doi: 10.1111/j.1460-9568.2009.06701.x

Robinson, D., Bucci, J., Fenn, H., Miller, T., Tinklenberg, J., and Yesavage, J. A. (1995). Erythrocyte sedimentation rate in Alzheimer's dementia. J. Am. Geriatr. Soc. 43, 1177-1178.

Shariat, A., Nazeri, M., Abolhasani Foroughi, A., and Karimi, M. (2013). Transcranial doppler ultrasonography in beta-thalassemia major patients without and with thrombocytosis. Iran. Red Crescent Med. J. 15, 234-238. doi: 10.5812/ircmj.4606

Shin, S., Ku, Y., Babu, N., and Singh, M. (2007). Erythrocyte deformability and its variation in diabetes mellitus. Indian J. Exp. Biol. 45, 121-128.

Shizukuda, Y., Bolan, C. D., Nguyen, T. T., Botello, G., Tripodi, D. J., Yau, Y. Y., et al. (2007). Oxidative stress in asymptomatic subjects with hereditary hemochromatosis. Am. J. Hematol. 82, 249-250. doi: 10.1002/ajh.20743

Shizukuda, Y., Bolan, C. D., Tripodi, D. J., Yau, Y. Y., Nguyen, T. T., Botello, G., et al. (2006). Significance of left atrial contractile function in asymptomatic subjects with hereditary hemochromatosis. Am. J. Cardiol. 98, 954-959. doi: 10.1016/j.amjcard.2006.04.040 
Smith, M. A., Zhu, X., Tabaton, M., Liu, G., McKeel, D. W. Jr., Cohen, M. L. et al. (2010). Increased iron and free radical generation in preclinical Alzheimer disease and mild cognitive impairment. J. Alzheimers Dis. 19, 363-372. doi: 10.3233/JAD-2010-1239

Starodubtseva, M. N., Kuznetsova, T. G., Yegorenkov, N. I., and Cherenkevich, S. N. (2008). Structural and mechanical characteristics of erythrocyte membranes in patients with type 2 diabetes mellitus. Bull. Exp. Biol. Med. 145, 99-103. doi: 10.1007/s10517-008-0036-3

Stewart, J. C., Villasmil, M. L., and Frampton, M. W. (2007). Changes in fluorescence intensity of selected leukocyte surface markers following fixation. Cytometry A 71, 379-385. doi: 10.1002/cyto.a.20392

Swanepoel, A. C., and Pretorius, E. (2012). Scanning electron microscopy analysis of erythrocytes in thromboembolic ischemic stroke. Int.J. Lab. Hematol. 34, 185-191. doi: 10.1111/j.1751-553X.2011.01379.x

Tateishi, N., Suzuki, Y., Cicha, I., and Maeda, N. (2001). $\mathrm{O}_{2}$ release from erythrocytes flowing in a narrow $\mathrm{O}_{2}$-permeable tube: effects of erythrocyte aggregation. Am. J. Physiol. Heart Circ. Physiol. 281, H448-H456.

Torti, F. M., and Torti, S. V. (2002). Regulation of ferritin genes and protein. Blood 99, 3505-3516. doi: 10.1182/blood.V99.10.3505

Tripathy, D., Sanchez, A., Yin, X., Luo, J., Martinez, J., and Grammas, P. (2013). Thrombin, a mediator of cerebrovascular inflammation in $\mathrm{AD}$ and hypoxia. Front. Aging Neurosci. 5:19. doi: 10.3389/fnagi.2013.00019

Tsuchiya, K., and Nitta, K. (2013). Hepcidin is a potential regulator of iron status in chronic kidney disease. Ther. Apher. Dial. 17, 1-8. doi: 10.1111/17449987.12001

Umur, E. E., Oktenli, C., Celik, S., Tangi, F., Sayan, O., Sanisoglu, Y. S., et al. (2011). Increased iron and oxidative stress are separately related to cognitive decline in elderly. Geriatr. Gerontol. Int. 11, 504-509. doi: 10.1111/j.14470594.2011.00694.x

Undas, A., and Ariëns, R. A. (2011). Fibrin clot structure and function: a role in the pathophysiology of arterial and venous thromboembolic diseases. Arterioscler. Thromb. Vasc. Biol. 31, e88-99. doi: 10.1161/ATVBAHA.111.230631

Wang, W., Knovich, M. A., Coffman, L. G., Torti, F. M., and Torti, S. V. (2010). Serum ferritin: past, present and future. Biochim. Biophys. Acta 1800, 760-769. doi: 10.1016/j.bbagen.2010.03.011

Wardman, P., and Candeias, L. P. (1996). Fenton chemistry: an introduction. Radiat. Res. 145, 523-531. doi: 10.2307/3579270
Weinberg, E. D. (2010). The hazards of iron loading. Metallomics 2, 732-740. doi: $10.1039 / \mathrm{c} 0 \mathrm{mt} 00023 \mathrm{j}$

Weisel, J. W. (2005). Fibrinogen and fibrin. Adv. Protein Chem. 70, 247-299. doi: 10.1016/S0065-3233(05)70008-5

Wong, B. (2011). Points of view: the overview figure. Nat. Methods 8:365. doi: 10.1038/nmeth0511-365

Wyss-Coray, T., and Rogers, J. (2012). Inflammation in Alzheimer disease-a brief review of the basic science and clinical literature. Cold Spring Harb. Perspect. Med. 2:a006346. doi: 10.1101/cshperspect.a006346

Zacharski, L. R., Shamayeva, G., and Chow, B. K. (2011). Effect of controlled reduction of body iron stores on clinical outcomes in peripheral arterial disease. Am. Heart J. 162, 949-957 e941. doi: 10.1016/j.ahj.2011. 08.013

Zegrean, M. (2009). Association of body iron stores with development of cardiovascular disease in the adult population: a systematic review of the literature. Can. J. Cardiovasc. Nurs. 19, 26-32.

Zhao, N., Sun, Z., Mao, Y., Hang, P., Jiang, X., Sun, L., et al. (2010). Myocardial iron metabolism in the regulation of cardiovascular diseases in rats. Cell. Physiol. Biochem. 25, 587-594. doi: 10.1159/000315077

Conflict of Interest Statement: The authors declare that the research was conducted in the absence of any commercial or financial relationships that could be construed as a potential conflict of interest.

Received: 24 October 2013; paper pending published: 05 November 2013; accepted: 20 November 2013; published online: 06 December 2013.

Citation: Bester J, Buys AV, Lipinski B, Kell DB and Pretorius E (2013) High ferritin levels have major effects on the morphology of erythrocytes in Alzheimer's disease. Front. Aging Neurosci. 5:88. doi: 10.3389/fnagi.2013.00088

This article was submitted to the journal Frontiers in Aging Neuroscience.

Copyright (C) 2013 Bester, Buys, Lipinski, Kell and Pretorius. This is an open-access article distributed under the terms of the Creative Commons Attribution License (CC BY). The use, distribution or reproduction in other forums is permitted, provided the original author(s) or licensor are credited and that the original publication in this journal is cited, in accordance with accepted academic practice. No use, distribution or reproduction is permitted which does not comply with these terms. 